\title{
Caracterização litoquímica e geocronológica de granitos do Batólito Águas Belas-Canindé, no Domínio Pernambuco-Alagoas, na Província Borborema
}

\author{
Lithochemistry and geochronological characterization of granites of Batólito \\ Águas Belas-Canindé, Domínio Pernambuco-Alagoas, Province Borborema
}

\begin{abstract}
Charles Henrique Fernandes Sales das Neves ${ }^{1}$ (D), Valderez Pinto Ferreira ${ }^{1}$ (D), Sergio Pacheco Neves ${ }^{1}$ 'Universidade Federal de Pernambuco - UFPE, Estrada do Curado, 538, Jardim São Paulo, CEP 50790400, Recife, PE, BR (charleshfs@hotmail.com; valderez@ufpe.br; serpane@hotlink.com.br)
\end{abstract}

Recebido em 2 de março de 2018; aceito em 16 de outubro de 2018

\section{Resumo}

Os Plútons Serra da Caiçara (616 \pm 3 milhões de anos - Ma), composto de hornblenda quartzo sienito a hornblenda quartzo álcali feldspato sienito grossos, Santana do Ipanema (621 $\pm 5 \mathrm{Ma})$, constituído por monzogranitos a sienogranitos equigranulares, e Maravilha (627 $\pm 5 \mathrm{Ma}$ ), formado por monzogranitos porfiríticos com forte foliação magmática, são algumas das intrusões que compõem o Batólito Águas Belas-Canindé, Domínio Pernambuco-Alagoas, Província Borborema, no nordeste do Brasil. As idades U-Pb em zircão (Sensitive High Resolution Ion Micro Probe - SHRIMP) dos plútons indicam intrusão associada ao período de formação da foliação de baixo ângulo regional, gerada durante a convergência da Orogênese Brasiliana. Os granitos e sienitos são cálcio-alcalinos de alto potássio a shoshoníticos, metaluminosos a levemente peraluminosos, da série magnetita granitos e magnesianos. Os padrões normalizados de elementos terras raras (ETR) para essas rochas indicam fracionamento moderado a alto, apresentando $(\mathrm{La} / \mathrm{Lu})_{\mathrm{N}}$ entre 14 e 82 e leves anomalias negativas de Eu. Diagramas de elementos incompatíveis normalizados em relação ao condrito mostram anomalias marcantes em NbTa e Ti, típicas de magmas relacionados a zonas de subducção. Anfibólios e biotitas, analisados nos três plútons, têm composições típicas de granitos da série cálcio-alcalina e possuem valores de Fe\# semelhantes aos da rocha total. O conjunto de dados geoquímicos sugere que o magma foi gerado em ambiente de arco, derivado da fusão de rochas basálticas de alto $\mathrm{K}$, em condições oxidantes, e evolui por cristalização fracionada.

Palavras-chave: Intrusões graníticas; Batólito Águas Belas-Canindé; Litoquímica; Geocronologia U-Pb em zircão (SHRIMP).

\begin{abstract}
The plutons Serra da Caiçara (616 $\pm 3 \mathrm{Ma})$, composed by coarse-grained hornblende quartz syenite to hornblende alkali quartz feldspar syenite; Santana do Ipanema (621 $\pm 5 \mathrm{Ma}$ ), monzogranites to equigranular sienogranites; and Maravilha $(627 \pm 5 \mathrm{Ma})$, porphyritic monzogranites with strong magmatic foliation, are some of the intrusions that make up Aguas Belas-Canindé Batholith, Dominio Pernambuco-Alagoas, Borborema Province, northeastern Brazil. The U-Pb (SHRIMP) ages in zircon of the plutons indicate intrusion associated with regional low-angle foliation, generated during the convergence of the Brasiliano Orogenesis. The granites and syenites are high-K calc-alkaline to shoshonitic, metaluminous to lightly peraluminous, of the magnetite granites and magnesian series. The chondrite-normalized REE patterns indicate moderate to high fractionation, present $(\mathrm{La} / \mathrm{Lu})_{\mathrm{N}}$ between 14 and 82, and slightly negative Eu anomalies. Chondrite-normalized incompatible elements show marked negative spikes in $\mathrm{Nb}$-Ta and $\mathrm{Ti}$, typical of magmas related to subduction zones. Amphibole and biotite of the three plutons have compositions typical of granites of calcalkaline series and have values of Fe \# similar to those of the total rock. Geochemical data suggest that the magma was generated in arc environment, derived from the fusion of high $\mathrm{K}$ basaltic rocks, under oxidizing conditions, and evolved by fractional crystallization.
\end{abstract}

Keywords: Granite intrusions; Batholithe Águas Belas-Canindé; Lithochemistry; SHRIMPU-Pb zircon age Geochronology. 


\section{INTRODUÇÃO}

Situada a norte do Cráton São Francisco, a Província Borborema (Almeida et al., 1981) foi afetada durante o neoproterozoico pela Orogênese Brasiliana, sendo este o principal evento tectônico da província (Brito Neves et al., 2000; Van Schmus et al., 2008). Entre as principais características dessa orogênese está o grande volume de magmas graníticos adicionado à crosta nesse período (Ferreira et al., 1998; Brito Neves et al., 2000; Guimarães et al., 2004; Van Schmus et al., 1995, 2008, 2011). Ao longo dos anos, a Província Borborema passou por compartimentações em domínios tectônicos (Brito Neves et al., 2000; Van Schmus et al., 2008), entre os quais está o Domínio Pernambuco-Alagoas (Van Schmus et al., 2008). Esse domínio é caracterizado por volumes grandes de intrusões ácidas e intermediárias que ocorrem como stocks e batólitos. Em acordo com o trabalho de Silva Filho et al. (2014), as intrusões ígneas do domínio foram agrupadas em pré-colisional (650-620 milhões de anos - Ma), sin-colisional (620-600 Ma), pós-colisional (580-550 Ma) e pós-tectônico (550-530 Ma).

O estudo dos granitos é uma ferramenta importante para o entendimento e a delimitação de eventos tectônicos e do desenvolvimento da crosta (Sial, 1986; Ferreira et al., 1998; Guimarães et al., 2004). O Domínio Pernambuco-Alagoas, um dos segmentos crustais da Província Borborema e importante para a formulação de modelos para a reconstrução continental do Gondwana, ainda é carente de dados geocronológicos e químicos em suas rochas, deixando algumas questões pendentes em relação à evolução e ao desenvolvimento delas.

Este trabalho faz uso de levantamentos de campo, petrografia, litoquímica de rocha total, química mineral e isotópicos (U-Pb em zircão) de três plútons graníticos (Santana do Ipanema, Maravilha e Serra da Caiçara), que fazem parte do Batólito Águas Belas-Canindé (Silva Filho et al., 2002) no Domínio Pernambuco-Alagoas, e tem como objetivo conhecer os mecanismos atuantes na formação e evolução desses plútons, possíveis fontes e ambientes tectônicos de formação e intrusão magmática.

\section{GEOLOGIA REGIONAL}

Com aproximadamente $450 \mathrm{mil} \mathrm{km}{ }^{2}$, a Província Borborema (Almeida et al., 1981) está situada ao norte do Cráton do São Francisco (Figura 1). Juntamente com sua respectiva porção situada na África, compreende uma grande província estrutural, formada durante a convergência e colisão dos crátons Oeste África-São Luiz, São Francisco-Congo e Amazônico, por volta de $\sim 600 \mathrm{Ma}$, durante a formação do Gondwana ocidental (Santos et al., 2004; Van Schmus et al., 2008). Esse evento é conhecido por Orogênese Brasiliana-/ Pan-Africana (Brito Neves et al., 2000).
Alguns autores sugerem uma evolução policíclica para a Província Borborema (Jardim de Sá e Hachspacher, 1980; Jardim de Sá, 1984; Jardim de Sá et al., 1986). Para esses autores, a maioria das faixas de dobramentos seria associada à Orogênese Transamazônica (eburniana), com retrabalhamento durante o Brasiliano. Santos $(1996,1998)$ sugeriu o modelo de acreção de terrenos tectono-estratigráficos como o principal mecanismo de acreção crustal. Para o autor, esses terrenos sofreram uma colagem tectono-estratigráfica nas margens de crátons, durante as Orogêneses Cariris Velho e Brasiliana-/Pan-Africana. A Cariris Velho, datada do fim do mesoproterozoico, começo do neoproterozoico, cronocorrelata com a Orogênese Grenvilleana, enquanto a Brasiliana-/Pan-Africana teria idade essencialmente neoproterozoica. Para outros autores, a Província Borborema juntamente com a Faixa de Dobramentos da África Central forma uma larga faixa Orogênica Brasiliana-/Pan-Africana (Van Schmus et al., 1995, 2008; Brito Neves et al., 1995; Silva Filho et al., 2002, 2007, 2010), resultado da convergência e colisão dos crátons São Luís-Oeste da África e São Francisco-Congo-Kasai, durante a formação do supercontinente Gondwana Ocidental.

A primeira parte da Orogênese Brasiliana é marcada por uma tectônica de baixo ângulo. No Domínio Pernambuco-Alagoas, essa tectônica afeta desde rochas dos Complexos Cabrobó e Belém do São Francisco a algumas intrusões graníticas, sendo marcada por linhas de estiramento principal NW-SE (Silva Filho et al., 2007). A idade para essa deformação é restrita entre 630 e 608 Ma (Guimarães et al., 2004; Neves et al., 2005a, 2005b; Neves et al., 2008). A fase de baixo ângulo é sucedida por uma transcorrente de alto ângulo, marcada pela formação de grandes estruturas com direção preferencial NE-SW (Neves et al., 2005a, 2005b; Neves et al., 2008).

Brito Neves et al. (2000) dividiram a Província Borborema em domínios tectônicos, os quais foram posteriormente renomeados por Van Schmus et al. (2008), de sul para norte: Sergipano, Pernambuco-Alagoas, Riacho do Pontal, Transversal, Rio Grande do Norte, Ceará e Médio Coreaú (Figura 1). Os Plútons Maravilha, Santana do Ipanema e Serra da Caiçara intrudem as rochas do Domínio Pernambuco-Alagoas, juntamente com outras intrusões Brasilianas, formando grandes batólitos ígneos (Brito Neves et al., 2000; Silva Filho et al., 2002, 2013; Van Schmus et al., 2008).

O Domínio Pernambuco-Alagoas consiste em uma sequência de biotita-granada gnaisses, com intercalação de quartzito, quartzo-xisto, rochas cálcio-silicáticas, anfibolitos, ortognaisses migmatizados que compõem o Complexo Cabrobó, e migmatitos e ortognaisses, que constituem o Complexo Belém do São Francisco (Santos, 1996; Medeiros e Santos, 1998). Silva Filho et al. (2002) sugerem uma idade de cristalização de 2079 \pm 34 Ma para o Complexo Belém do São Francisco, e Brito Neves et al. (1995) indicam idade de $966 \pm 14$ Ma para o Complexo Cabrobó. 
Os principais corpos graníticos do Domínio PernambucoAlagoas podem ser agrupados em cinco grandes batólitos (Figura 1), sendo eles: Buíque-Paulo Afonso, Águas Belas-Canindé, Marimbondo-Correntes, Ipojuca-Atalaia e Garanhuns (Silva Filho et al., 2002). Os plútons alvos deste trabalho fazem parte do Batólito Águas Belas-Canindé, que intrudem metatexitos ortoderivados e diatexitos de composição intermediária a ácida (Silva Filho et al., 2002). Baseando-se-em idades $\mathrm{T}_{\mathrm{DM}}$, Van Schmus et al. (2008) separaram as rochas do Domínio Pernambuco-Alagoas em cinco agrupamentos: $\mathrm{T}_{\mathrm{DM}}(\mathrm{Sm} / \mathrm{Nd})$ superior a $2,40 \mathrm{Ga}$, representada por várias ocorrências locais de gnaisses e migmatitos; $\mathrm{T}_{\mathrm{DM}}(\mathrm{Sm} / \mathrm{Nd})$ entre 2,00 e $2,20 \mathrm{Ga}$, representada por grandes áreas na metade do nordeste do Domínio PernambucoAlagoas; $\mathrm{T}_{\mathrm{DM}}(\mathrm{Sm} / \mathrm{Nd})$ entre 1,70 e 2,00 Ga, representada por vários plútons no canto nordeste do domínio; $\mathrm{T}_{\mathrm{DM}}(\mathrm{Sm} / \mathrm{Nd})$ entre 1,20 e $1,50 \mathrm{Ga}$, representada por grande partes da metade sudoeste do Domínio Pernambuco-Alagoas; e $\mathrm{T}_{\mathrm{DM}}$ $(\mathrm{Sm} / \mathrm{Nd})$ entre 0,90 e 1,20 Ga, representada principalmente pelo Batólito Buíque-Paulo Afonso. Os plútons do Batólito Águas Belas-Canindé possuem idade $\mathrm{T}_{\mathrm{DM}}(\mathrm{Sm} / \mathrm{Nd})$ de aproximadamente $1,40 \mathrm{Ga}$, refletindo mistura de processos entre uma crosta enriquecida paleoproterozoica e material juvenil Brasiliano ou Cariris Velho (Silva Filho et al., 2002).

\section{METODOLOGIA}

Para este trabalho, foram coletadas amostras representativas dos três plútons. Algumas amostras foram selecionadas para a confecção de lâminas delgadas, que posteriormente foram encaminhadas para análises químicas por microssonda eletrônica $\left(\mathrm{JEOL}^{\circledR}\right.$, modelo JXA-8230, com cinco espectrômetros WDS e um EDS) da Universidade de Brasília. As condições

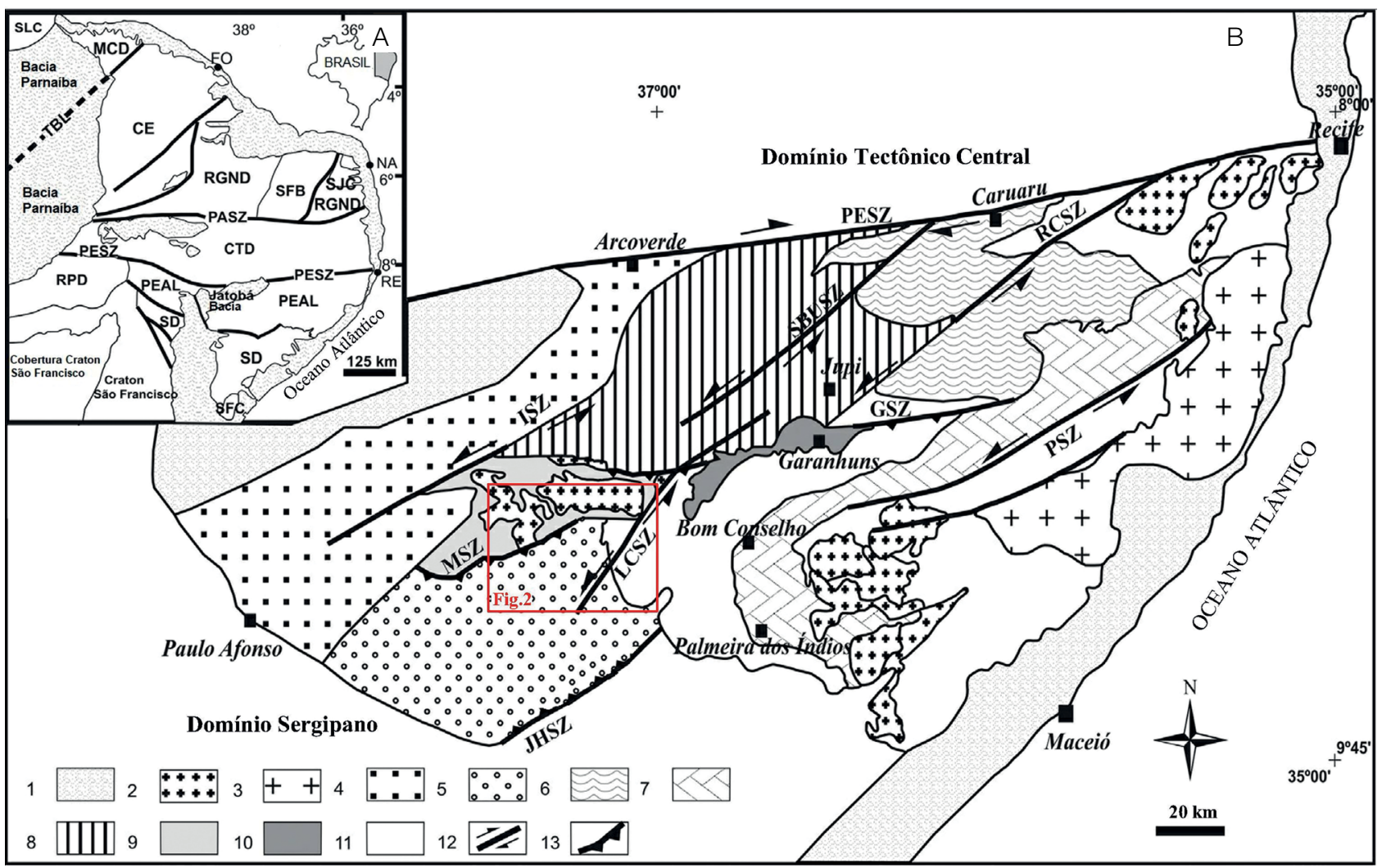

CE: Domínio Ceará; MCD: Domínio Médio Coreaú; PEAL: Domínio Pernambuco-Alagoas; RGND: Domínio Rio Grande do Norte (SJC: Núcleo Arqueano São José Do Campestre; SFB: Faixa de Dobramento Seridó); RPD: Domínio Riacho Pontal; SD: Domínio Sergipano; SFC: Cráton São Francisco; SLC: Cráton São Luís; DZT: Domínio da Central; PaSZ: Zona de Cisalhamento Patos; PeSZ: Zona de Cisalhamento Pernambuco; SMASZ: Zona de Cisalhamento São Miguel do Aleixo; FO: Fortaleza; NA: Natal; RE: Recife; 1: cobertura sedimentar palaeozoica; 2: Granitoides Brasilianos; 3: Batólito Ipojuca-Atalaia; 4: Batólito Buíque-Paulo Afonso; 5: Batólito composto Águas Belas-Canindé; 6: Batólito Garanhuns; 7: Sequência Palmares; 8: Sequência Venturosa; 9: Sequência Inhapi; 10: Quartzito Garanhuns; 11: Complexo Belém do São Francisco; 12: Zonas de Cisalhamento Transcorrentes (PESZ: Pernambuco; RCSZ: Rio da Chata; PSZ: Palmares; LCSZ: Limitão Caetés; ISZ: Itaíba; SBUSZ: São Bento do Una); 13: Zonas de Cisalhamento Transpressivas (GSZ: Garanhuns; MSZ: Maravilha; ZCJH: Jacaré dos Homens) (Silva Filho et al., 2010). Retângulo em vermelho marca a área do mapa da Figura 2.

Figura 1. (A) Província de Borborema com principais domínios de acordo com Van Schmus et al. (2008). (B) Mapa geológico simplificado da parte oriental do domínio Pernambuco-Alagoas. 
analíticas foram voltagem de aceleração de $15 \mathrm{kV}$, corrente de $10 \mathrm{nA}$, e um diâmetro do feixe eletrônico da ordem de $5 \mu$, em que foi obtida a composição química dos diversos minerais constituintes das rochas. Os valores obtidos são apresentados nas Tabelas 1, 2 e 3.
Os elementos maiores e alguns elementos traços de amostras selecionadas foram analisados por fluorescência de raios X em um espectrômetro ZSX Primus II da Rigaku $^{\circledast}$, no Departamento de Geologia (NEG-LABISE) da Universidade Federal de Pernambuco (UFPE), em Recife,

Tabela 1. Composição química e proporções catiônicas para análises representativas de biotita dos Plútons Maravilha e Santana do Ipanema.

\begin{tabular}{|c|c|c|c|c|c|c|}
\hline \multirow{2}{*}{ Amostra } & \multicolumn{4}{|c|}{ Maravilha } & \multicolumn{2}{|c|}{ Santana do Ipanema } \\
\hline & CH-1-1 & $\mathrm{CH}-1-1$ & $\mathrm{CH}-1-2$ & $\mathrm{CH}-1-2$ & $\mathrm{CH}-17-1$ & $\mathrm{CH}-17-1$ \\
\hline Localização & Centro & Borda & Centro & Borda & Centro & Borda \\
\hline $\mathrm{SiO}_{2}$ & 35,988 & 35,943 & 35,852 & 36,123 & 37,599 & 36,483 \\
\hline $\mathrm{TiO}_{2}^{2}$ & 2,268 & 2,927 & 2,27 & 2,214 & 1,786 & 1,926 \\
\hline $\mathrm{Al}_{2} \mathrm{O}_{3}$ & 14,353 & 14,736 & 14,665 & 14,697 & 14,133 & 13,668 \\
\hline $\mathrm{FeO}^{2}$ & 20,867 & 19,874 & 19,658 & 19,999 & 17,641 & 17,81 \\
\hline $\mathrm{MnO}$ & 0,546 & 0,61 & 0,43 & 0,372 & 0,204 & 0,236 \\
\hline $\mathrm{MgO}$ & 10,648 & 11,252 & 10,936 & 11,367 & 12,841 & 13,048 \\
\hline $\mathrm{CaO}$ & 0,011 & 0 & 0,021 & 0,052 & 0 & 0,117 \\
\hline $\mathrm{Na}_{2} \mathrm{O}$ & 0,074 & 0,081 & 0,069 & 0,106 & 0,041 & 0,102 \\
\hline $\mathrm{K}_{2} \mathrm{O}^{2}$ & 9,804 & 9,637 & 9,619 & 9,448 & 10,044 & 9,902 \\
\hline $\mathrm{SrO}^{2}$ & 0,077 & 0,066 & 0,109 & 0,075 & 0,059 & 0,03 \\
\hline $\mathrm{BaO}$ & 0,163 & 0,175 & 0,035 & 0,046 & 0 & 0,317 \\
\hline $\mathrm{F}$ & 0,548 & 0,529 & 0,567 & 0,602 & 1,44 & 1,407 \\
\hline $\mathrm{Cl}$ & 0,011 & 0,003 & 0,029 & 0,014 & 0,033 & 0,082 \\
\hline $\mathrm{Cr}_{2} \mathrm{O}_{3}$ & 0,002 & 0 & 0,035 & 0 & 0 & 0,001 \\
\hline $\mathrm{NiO}$ & 0 & 0 & 0,033 & 0,045 & 0 & 0,09 \\
\hline $\mathrm{Li}_{2} \mathrm{O}^{*}$ & 0,78 & 0,76 & 0,74 & 0,82 & 1,24 & 0,92 \\
\hline $\mathrm{H}_{2} \mathrm{O}^{*}$ & 3,62 & 3,68 & 3,59 & 3,62 & 3,29 & 3,21 \\
\hline Subtotal & 99,76 & 100,27 & 98,66 & 99,60 & 100,35 & 99,35 \\
\hline $\mathrm{O}=\mathrm{F}, \mathrm{Cl}$ & 0,23 & 0,22 & 0,25 & 0,26 & 0,61 & 0,61 \\
\hline Total & 99,53 & 100,05 & 98,41 & 99,34 & 99,73 & 98,74 \\
\hline $\mathrm{Si}$ & 5,554 & 5,487 & 5,554 & 5,539 & 5,669 & 5,606 \\
\hline Al IV & 2,446 & 2,513 & 2,446 & 2,461 & 2,331 & 2,394 \\
\hline $\mathrm{Al} \mathrm{VI}$ & 0,164 & 0,138 & 0,232 & 0,196 & 0,181 & 0,081 \\
\hline $\mathrm{Ti}$ & 0,263 & 0,336 & 0,264 & 0,255 & 0,203 & 0,223 \\
\hline $\mathrm{Cr}$ & 0,000 & 0,000 & 0,004 & 0,000 & 0,000 & 0,000 \\
\hline $\mathrm{Fe}$ & 2,693 & 2,537 & 2,547 & 2,565 & 2,224 & 2,289 \\
\hline $\mathrm{Mn}$ & 0,071 & 0,079 & 0,056 & 0,048 & 0,026 & 0,031 \\
\hline $\mathrm{Mg}$ & 2,450 & 2,560 & 2,526 & 2,598 & 2,886 & 2,989 \\
\hline $\mathrm{Ni}$ & 0,000 & 0,000 & 0,004 & 0,006 & 0,000 & 0,011 \\
\hline $\mathrm{Li}^{*}$ & 0,482 & 0,469 & 0,460 & 0,503 & 0,751 & 0,568 \\
\hline $\mathrm{Ca}$ & 0,002 & 0,000 & 0,003 & 0,009 & 0,000 & 0,019 \\
\hline $\mathrm{Na}$ & 0,022 & 0,024 & 0,021 & 0,032 & 0,012 & 0,030 \\
\hline K & 1,930 & 1,876 & 1,901 & 1,848 & 1,932 & 1,941 \\
\hline $\mathrm{Sr}$ & 0,007 & 0,006 & 0,010 & 0,007 & 0,005 & 0,003 \\
\hline $\mathrm{Ba}$ & 0,010 & 0,010 & 0,002 & 0,003 & 0,000 & 0,019 \\
\hline $\mathrm{OH}^{\star}$ & 3,730 & 3,744 & 3,715 & 3,704 & 3,305 & 3,295 \\
\hline $\mathrm{F}$ & 0,267 & 0,255 & 0,278 & 0,292 & 0,687 & 0,684 \\
\hline $\mathrm{Cl}$ & 0,003 & 0,001 & 0,008 & 0,004 & 0,008 & 0,021 \\
\hline Cátion total & 20,095 & 20,036 & 20,031 & 20,068 & 20,220 & 20,203 \\
\hline $\mathrm{Fe} / \mathrm{Fe}+\mathrm{Mg}$ & 0,524 & 0,498 & 0,502 & 0,497 & 0,435 & 0,434 \\
\hline
\end{tabular}

Fórmula calculada com base em 24 oxigênios. 
Tabela 2. Composição química e proporções catiônicas de anfibólio com base em 23 oxigênios. Amostras representativas dos Plútons Maravilha, Santana do Ipanema e Serra da Caiçara.

\begin{tabular}{|c|c|c|c|c|c|c|c|c|c|c|c|c|}
\hline \multirow[b]{2}{*}{ Amostras } & \multicolumn{4}{|c|}{ Serra da Caiçara } & \multicolumn{4}{|c|}{ Santana do Ipanema } & \multicolumn{4}{|c|}{ Maravilha } \\
\hline & $\begin{array}{l}\mathrm{CH}- \\
81-1\end{array}$ & $\begin{array}{l}\mathrm{CH}- \\
81-1\end{array}$ & $\begin{array}{l}\mathrm{CH}- \\
81-2\end{array}$ & $\begin{array}{l}\mathrm{CH}- \\
81-2\end{array}$ & $\begin{array}{l}\mathrm{CH}- \\
17-1\end{array}$ & $\begin{array}{l}\mathrm{CH}- \\
17-1\end{array}$ & $\begin{array}{l}\mathrm{CH}- \\
17-2\end{array}$ & $\begin{array}{l}\mathrm{CH}- \\
17-2\end{array}$ & $\begin{array}{c}\mathrm{CH}- \\
1-1\end{array}$ & $\begin{array}{c}\mathrm{CH}- \\
1-1\end{array}$ & $\begin{array}{l}\mathrm{CH}- \\
1-2\end{array}$ & $\begin{array}{c}\mathrm{CH}- \\
1-2\end{array}$ \\
\hline Localização & Centro & Borda & Centro & Borda & Centro & Borda & Centro & Borda & Centro & Borda & Centro & Borda \\
\hline $\mathrm{SiO}_{2}$ & 45,64 & 43,71 & 45,39 & 44,33 & 44,98 & 42,91 & 44,07 & 42,96 & 42,13 & 39,58 & 41,22 & 42,07 \\
\hline $\mathrm{TiO}_{2}^{2}$ & 1,051 & 0,525 & 0,335 & 0,521 & 1,103 & 0,889 & 1,159 & 0,713 & 0,838 & 0,348 & 1,131 & 1,153 \\
\hline $\mathrm{Al}_{2} \mathrm{O}_{3}$ & 7,495 & 8,329 & 7,528 & 8,496 & 7,344 & 9,033 & 8,448 & 9,159 & 9,647 & 12,49 & 10,12 & 9,827 \\
\hline $\mathrm{FeO}^{2}$ & 18,33 & 19,78 & 18,81 & 19,98 & 18,30 & 19,16 & 19,77 & 20,52 & 20,43 & 23,46 & 20,09 & 20,44 \\
\hline $\mathrm{MnO}$ & 0,561 & 0,853 & 0,774 & 0,842 & 0,456 & 0,56 & 0,428 & 0,538 & 0,544 & 0,675 & 0,677 & 0,714 \\
\hline $\mathrm{MgO}$ & 10,54 & 9,572 & 10,08 & 9,625 & 11,37 & 9,88 & 9,787 & 9,667 & 8,781 & 6,373 & 8,831 & 8,33 \\
\hline $\mathrm{CaO}$ & 11,25 & 11,10 & 11,60 & 10,90 & 11,50 & 11,72 & 11,63 & 11,56 & 11,51 & 11,44 & 11,57 & 11,40 \\
\hline $\mathrm{Na}_{2} \mathrm{O}$ & 1,665 & 1,732 & 1,177 & 1,816 & 1,032 & 1,568 & 1,268 & 1,252 & 1,398 & 1,29 & 1,248 & 1,318 \\
\hline $\mathrm{K}_{2} \mathrm{O}^{2}$ & 1,118 & 1,182 & 1,232 & 1,21 & 1,02 & 1,231 & 1,24 & 1,303 & 1,226 & 1,421 & 1,279 & 1,207 \\
\hline Total & 97,67 & 96,79 & 96,95 & 97,74 & 97,12 & 96,96 & 97,81 & 97,68 & 96,51 & 97,09 & 96,18 & 96,46 \\
\hline $\mathrm{Si}$ & 6,837 & 6,650 & 6,866 & 6,662 & 6,712 & 6,528 & 6,632 & 6,470 & 6,461 & 6,107 & 6,339 & 6,462 \\
\hline Al iv & 1,163 & 1,350 & 1,134 & 1,338 & 1,288 & 1,472 & 1,368 & 1,530 & 1,539 & 1,893 & 1,661 & 1,538 \\
\hline Al vi & 0,160 & 0,143 & 0,209 & 0,166 & 0,004 & 0,147 & 0,130 & 0,096 & 0,204 & 0,379 & 0,173 & 0,241 \\
\hline $\mathrm{Ti}$ & 0,118 & 0,060 & 0,038 & 0,059 & 0,124 & 0,102 & 0,131 & 0,081 & 0,097 & 0,040 & 0,131 & 0,133 \\
\hline $\mathrm{Fe}^{3+}$ & 0,459 & 0,729 & 0,503 & 0,782 & 0,864 & 0,597 & 0,616 & 0,925 & 0,703 & 0,985 & 0,792 & 0,649 \\
\hline $\mathrm{Fe}^{2+}$ & 1,838 & 1,788 & 1,877 & 1,730 & 1,420 & 1,841 & 1,873 & 1,660 & 1,917 & 2,042 & 1,792 & 1,977 \\
\hline $\mathrm{Mn}$ & 0,071 & 0,110 & 0,099 & 0,107 & 0,058 & 0,072 & 0,055 & 0,069 & 0,071 & 0,088 & 0,088 & 0,093 \\
\hline $\mathrm{Mg}$ & 2,354 & 2,171 & 2,274 & 2,156 & 2,530 & 2,241 & 2,196 & 2,170 & 2,007 & 1,466 & 2,024 & 1,907 \\
\hline $\mathrm{Ca}$ & 1,805 & 1,809 & 1,881 & 1,756 & 1,840 & 1,912 & 1,876 & 1,866 & 1,891 & 1,892 & 1,906 & 1,876 \\
\hline $\mathrm{Na}$ & 0,483 & 0,511 & 0,345 & 0,529 & 0,299 & 0,462 & 0,370 & 0,366 & 0,416 & 0,386 & 0,372 & 0,393 \\
\hline K & 0,214 & 0,229 & 0,238 & 0,232 & 0,194 & 0,239 & 0,238 & 0,250 & 0,240 & 0,280 & 0,251 & 0,237 \\
\hline Cátio & 17,503 & 17,549 & 17,464 & 17,517 & 17,332 & 17,613 & 17,484 & 17,482 & 17,547 & 17,557 & 17,529 & 17,505 \\
\hline $\mathrm{T}(\mathrm{HeB}, 1994)$ & & & & & & & & & 744,5 & 766,6 & 747,1 & 759,3 \\
\hline $\mathrm{P}(\mathrm{AeS}, 1995)$ & & & & & & & & & 4,66 & 6,39 & 5,02 & 4,47 \\
\hline$P(S, 1992)$ & 3,3 & 4,1 & 3,4 & 4,2 & 3,1 & 4,7 & 4,1 & 4,7 & 5,3 & 7,8 & 5,7 & 5,5 \\
\hline
\end{tabular}

Temperatura em ${ }^{\circ} \mathrm{C}$ calculada usando Holland e Blundy (1994) (HeB, 1994); pressão em kbar calculada por Anderson e Smith (1995) (AeS, 1995) e Schmidt (1992) (S, 1992).

Tabela 3. Composição química e proporções catiônicas de plagioclásio, com base em oito oxigênios. Amostras representativas dos Plútons Serra da Caiçara e Maravilha.

\begin{tabular}{lcccccccc}
\hline \multirow{2}{*}{ Amostras } & \multicolumn{4}{c}{ Serra da Caiçara } & \multicolumn{4}{c}{ Maravilha } \\
\cline { 2 - 9 } & CH-81-1 & CH-81-1 & CH-81-2 & CH-81-2 & CH-1-1 & CH-1-1 & CH-1-2 & CH-1-2 \\
\hline Localização & Centro & Borda & Centro & Borda & Centro & Borda & Centro & Borda \\
\hline $\mathrm{SiO}_{2}$ & 67,335 & 66,711 & 67,948 & 65,876 & 60,839 & 61,348 & 60,157 & 60,663 \\
$\mathrm{TiO}_{2}$ & 0,101 & 0,102 & 0 & 0 & 0,134 & 0 & 0 & 0 \\
$\mathrm{Al}_{2} \mathrm{O}_{3}$ & 20,189 & 19,493 & 19,589 & 20,424 & 23,437 & 22,929 & 23,32 & 23,493 \\
$\mathrm{Cr}_{2} \mathrm{O}_{3}$ & 0,098 & 0,038 & 0 & 0,075 & 0 & 0 & 0,038 & 0 \\
$\mathrm{FeO}$ & 0,045 & 0,204 & 0,054 & 0,059 & 0,215 & 0,097 & 0,072 & 0,008 \\
$\mathrm{MnO}$ & 0 & 0,047 & 0,059 & 0 & 0 & 0,046 & 0,045 & 0,083 \\
$\mathrm{MgO}$ & 0 & 0,017 & 0,021 & 0 & 0 & 0,014 & 0,012 & 0,013 \\
$\mathrm{CaO}$ & 0,91 & 0,606 & 0,539 & 2,029 & 5,396 & 4,685 & 5,636 & 5,115 \\
$\mathrm{BaO}$ & 0 & 0 & 0 & 0 & 0,03 & 0,093 & 0,106 & 0,049 \\
$\mathrm{Na}$ & 11,214 & 11,512 & 11,253 & 10,53 & 8,238 & 8,612 & 8,468 & 8,476 \\
$\mathrm{~K}_{2} \mathrm{O}$ & 0,099 & 0,071 & 0,095 & 0,095 & 0,238 & 0,15 & 0,214 & 0,133 \\
Total & 99,991 & 98,801 & 99,558 & 99,088 & 98,527 & 97,974 & 98,068 & 98,033 \\
\hline
\end{tabular}


Tabela 3. Continuação.

\begin{tabular}{lcccccccc}
\hline \multirow{2}{*}{ Amostras } & \multicolumn{4}{c}{ Serra da Caiçara } & \multicolumn{4}{c}{ Maravilha } \\
\cline { 2 - 9 } & CH-81-1 & CH-81-1 & CH-81-2 & CH-81-2 & CH-1-1 & CH-1-1 & CH-1-2 & CH-1-2 \\
\hline Localização & Centro & Borda & Centro & Borda & Centro & Borda & Centro & Borda \\
\hline $\mathrm{Si}$ & 2,949 & 2,950 & 2,989 & 2,921 & 2,745 & 2,777 & 2,721 & 2,744 \\
$\mathrm{Ti}$ & 0,003 & 0,003 & 0 & 0 & 0,005 & 0 & 0 & 0 \\
$\mathrm{Al}$ & 1,042 & 1,016 & 1,015 & 1,067 & 1,246 & 1,223 & 1,243 & 1,252 \\
$\mathrm{Cr}$ & 0,003 & 0,001 & 0 & 0,003 & 0 & 0 & 0,001 & 0 \\
$\mathrm{Fe}{ }^{2+}$ & 0,002 & 0,008 & 0,002 & 0,002 & 0,008 & 0,004 & 0,003 & 0 \\
$\mathrm{Ca}$ & 0,043 & 0,029 & 0,025 & 0,096 & 0,261 & 0,227 & 0,273 & 0,248 \\
$\mathrm{Na}$ & 0,952 & 0,987 & 0,960 & 0,905 & 0,721 & 0,756 & 0,743 & 0,743 \\
$\mathrm{~K}$ & 0,006 & 0,004 & 0,005 & 0,005 & 0,014 & 0,009 & 0,012 & 0,008 \\
$\mathrm{Cátion} \mathrm{total}$ & 5,00 & 5,00 & 5,00 & 5,00 & 5,00 & 5,00 & 5,00 & 5,00 \\
\hline An & 4,26 & 2,81 & 2,56 & 9,57 & 26,21 & 22,91 & 26,56 & 24,81 \\
$\mathrm{Ab}$ & 95,17 & 96,79 & 96,89 & 89,89 & 72,41 & 76,21 & 72,23 & 74,41 \\
Or & 0,55 & 0,39 & 0,53 & 0,53 & 1,37 & 0,87 & 1,20 & 0,76 \\
\hline
\end{tabular}

Brasil. Foram usados discos fundidos e aplicado o padrão método de curvas de calibração, preparadas com materiais de referência certificados. Os elementos terras raras (ETR) foram analisados pelo ICP-OES no SGS-Geosol Laboratório, em Belo Horizonte, Brasil. Os valores obtidos para os elementos maiores, traços e ETR são apresentados na Tabela 4.

Os dados isotópicos de U-Pb em zircão (Sensitive High Resolution Ion Micro Probe - SHRIMP) foram determinados na fração não magnética dos Plútons Maravilha (monzogranitos) e Santana do Ipanema (sienogranitos a monzogranitos). Não foram realizadas datações no Plúton Serra da Caiçara, visto que este já apresenta uma datação na literatura, $616 \pm 3 \mathrm{Ma}$ (U-Pb SHRIMP) (Mendes et al., 2009). Os grãos de zircão foram separados usando esmagamento padrão, peneirador (para separação da fração desejada, 0,150-0,063 mm), separador magnético e separação de líquidos densos. Os concentrados de zircão foram limpos usando ácido fluoreto de hidrogênio (HF) concentrado, seguido de ácido sulfúrico $\left(\mathrm{H}_{2} \mathrm{SO}_{4}\right)$. Os grãos de zircão foram montados em fita adesiva dupla-face antes de serem colocados em um disco epóxi com resina e polidos para revelar a parte interna, removendo a parte externa dos cristais de zircão. Os grãos foram fotografados em luzes refletidas e transmitidas. As imagens de cátodo luminescência (CL) foram produzidas em um microscópio eletrônico de varredura, com a finalidade de investigar as estruturas internas dos cristais de zircão, para caracterizar diferentes populações e assegurar que o ponto esteja totalmente dentro de um componente de idade único dentro dos grãos selecionados. As taxas de isótopos U-Pb foram determinadas usando SHRIMP II no GeoLab-IGc-USP, em São Paulo, Brasil. Os pontos analíticos individuais para as análises SHRIMP possuíam cerca de $20 \mu$ de diâmetro. As análises foram realizadas nos núcleos, onde não apresentavam excesso de crescimento. Os dados foram processados e os valores de ${ }^{207} \mathrm{~Pb} /{ }^{235} \mathrm{U} \mathrm{e}^{206} \mathrm{~Pb} /{ }^{238} \mathrm{U}$ corrigidos foram plotados em diagramas concórdia convencionais, usando o software ISOPLOT. Na Tabela 5 é apresentado um resumo dos valores de U-Pb obtidos.

Durante as atividades de campo, foram obtidos valores de susceptibilidade magnética dos plútons. Os valores são alcançados tanto em amostras com $5 \mathrm{~cm}$ de aresta como em faces frescas da rocha in situ. Para medir a susceptibilidade magnética, foi utilizado um susceptibilímetro manual Kappameter $^{\circledR}$, modelo KT-5. Em cada ponto, foram realizadas, em média, três medições de susceptibilidade para melhorar a confiabilidade da aferição. Os valores médios de susceptibilidade magnética são apresentados no item Fugacidade de Oxigênio.

\section{FEIÇÕES DE CAMPO E PETROGRAFIA}

Os Plútons Maravilha, Santana do Ipanema e Serra da Caiçara estão em contato direto um com o outro (Figura 2) e afloram na porção noroeste do Batólito Águas Belas-Canindé. As intrusões apresentam elementos estruturais que indicam atuação de tectônica de baixo ângulo - como linhas de estiramento NW-SE (com caimento baixo), tramas S-C e dobramento da foliação - , bem como elementos estruturais indicativos de tectônica transcorrente - como bandas de cisalhamento, corredores de foliação milonítica de alto ângulo, deformação dúctil em K-feldspato e quartzo e enclaves anfibolíticos com aproximadamente $1 \mathrm{~m}$, orientados NE-SW (Sales das Neves et al., 2017).

O Plúton Serra da Caiçara (Figuras 2 e 3) é a menor das três intrusões, com cerca de $90 \mathrm{~km}^{2}$, sendo constituído de 
Tabela 4. Dados químicos de rocha total. Amostras representativas dos Plútons Serra da Caiçara, Santana do Ipanema e Maravilha.

\begin{tabular}{|c|c|c|c|c|c|c|c|c|c|}
\hline \multirow{2}{*}{ Amostra } & \multicolumn{3}{|c|}{ Maravilha } & \multicolumn{3}{|c|}{ Santana do Ipanema } & \multicolumn{3}{|c|}{ Serra da Caiçara } \\
\hline & $\mathrm{CH}-01$ & $\mathrm{CH}-02$ & $\mathrm{CH}-03 \mathrm{~B}$ & $\mathrm{CH}-14$ & $\mathrm{CH}-17$ & $\mathrm{CH}-30$ & $\mathrm{CH}-36$ & $\mathrm{CH}-51$ & $\mathrm{CH}-07$ \\
\hline $\mathrm{SiO}_{2}$ & 62,71 & 70,88 & 66,91 & 74,85 & 63,94 & 75,6 & 67,29 & 67,16 & 64,92 \\
\hline $\mathrm{Al}_{2} \mathrm{O}_{3}$ & 15,81 & 18,92 & 16,7 & 16,03 & 15,12 & 14,49 & 15,71 & 14,96 & 16,45 \\
\hline $\mathrm{Fe}_{2} \mathrm{O}_{3}$ & 4,06 & 2,45 & 4,05 & 1,39 & 4,52 & 1,84 & 3,69 & 3,83 & 1,75 \\
\hline $\mathrm{CaO}$ & 3,51 & 1,29 & 3,74 & 0,81 & 2,75 & 1,41 & 2,04 & 2,14 & 3,95 \\
\hline $\mathrm{Na}_{2} \mathrm{O}$ & 4,48 & 2,62 & 4,83 & 5,44 & 4,45 & 4,22 & 3,78 & 3,71 & 2,14 \\
\hline $\mathrm{K}_{2} \mathrm{O}$ & 3,19 & 3,38 & 2,95 & 4,72 & 4,69 & 5,22 & 7,14 & 6,69 & 4,3 \\
\hline $\mathrm{MgO}$ & 1,36 & 0,69 & 1,41 & 0,2 & 1,59 & 0,49 & 0,9 & 0,92 & 2,13 \\
\hline $\mathrm{TiO}_{2}$ & 0,59 & 0,45 & 0,64 & 0,12 & 0,66 & 0,24 & 0,64 & 0,61 & 1,28 \\
\hline $\mathrm{P}_{2} \mathrm{O}_{5}$ & 0,21 & 0,12 & 0,23 & 0,03 & 0,23 & 0,09 & 0,25 & 0,23 & 0,79 \\
\hline $\mathrm{MnO}$ & 0,08 & 0,02 & 0,08 & 0,04 & 0,07 & 0,03 & 0,07 & 0,08 & 0,04 \\
\hline $\mathrm{Cr}_{2} \mathrm{O}_{3}$ & $<0,01$ & & 0,01 & $<0,01$ & & 0,03 & $<0,01$ & 0,01 & \\
\hline LOI & 0,51 & & 0,94 & 0,35 & & 0,62 & 0,4 & 0,4 & \\
\hline $\mathrm{Ba}$ & 1488 & 1.312 & 1344 & 2.015 & 1412 & 1.803 & 5.305 & 4.691 & 2.128 \\
\hline $\mathrm{Sr}$ & 581 & 4.038 & 771 & 739 & 737 & 911 & 1.864 & 1.747 & 1.352 \\
\hline $\mathrm{Zn}$ & 66 & & 81 & 36 & & 41 & 69 & 78 & \\
\hline $\mathrm{Zr}$ & 237 & 1.180 & 234 & 131 & 364 & 155 & 412 & 411 & 136 \\
\hline $\mathrm{Ce}$ & 66,6 & & 83,1 & 21,1 & & 68,2 & 191 & 199,2 & \\
\hline Co & 8,6 & & 8 & 1,7 & & 4,6 & 5,8 & 5,9 & \\
\hline Cs & 3,3 & & 2,01 & 4,5 & & 2,46 & 1,84 & 1,98 & \\
\hline $\mathrm{Cu}$ & 14 & & 12 & $<5$ & & 5 & 10 & 6 & \\
\hline Dy & 3,2 & & 4,07 & 0,95 & & 1,88 & 5,85 & 6,18 & \\
\hline $\mathrm{Er}$ & 1,71 & & 2,07 & 0,63 & & 0,89 & 2,5 & 2,58 & \\
\hline $\mathrm{Eu}$ & 1,04 & & 1,42 & 0,16 & & 0,96 & 3,16 & 3,23 & \\
\hline $\mathrm{Ga}$ & 18,4 & & 21,4 & 17,2 & & 20,4 & 21,3 & 20,6 & \\
\hline Gd & 4,27 & & 5,32 & 0,97 & & 3,43 & 11,31 & 11,49 & \\
\hline $\mathrm{Hf}$ & 5,63 & & 5,86 & 3,51 & & 4,3 & 11,26 & 10,32 & \\
\hline Ho & 0,61 & & 0,75 & 0,2 & & 0,33 & 1,01 & 1,05 & \\
\hline La & 34,8 & & 39,1 & 6,6 & & 39,9 & 100,8 & 107,8 & \\
\hline Lu & 0,18 & & 0,22 & 0,05 & & 0,05 & 0,24 & 0,23 & \\
\hline Mo & 4 & & 3 & 3 & & 6 & 5 & 3 & \\
\hline $\mathrm{Nb}$ & 10,1 & & 14,96 & 13,52 & & 12,19 & 26,26 & 25,74 & \\
\hline $\mathrm{Nd}$ & 27,7 & & 37,1 & 3,7 & & 25,9 & 85,3 & 86,5 & \\
\hline $\mathrm{Ni}$ & 12 & & 10 & 22 & & 22 & 18 & 12 & \\
\hline $\operatorname{Pr}$ & 7,5 & & 9,71 & 0,96 & & 7,26 & 22,18 & 22,81 & \\
\hline $\mathrm{Rb}$ & 89,5 & & 86 & 116,5 & & 132,8 & 142 & 136,7 & \\
\hline $\mathrm{Sm}$ & 4,7 & & 6,6 & 0,9 & & 4,5 & 14,8 & 15 & \\
\hline Sn & 1,8 & & 2,6 & 2 & & 2,1 & 4,3 & 3,9 & \\
\hline $\mathrm{Ta}$ & 0,77 & & 1,08 & 0,7 & & 0,93 & 2,08 & 1,59 & \\
\hline $\mathrm{Tb}$ & 0,58 & & 0,76 & 0,16 & & 0,42 & 1,35 & 1,38 & \\
\hline Th & 8,4 & & 9 & 7,7 & & 26 & 19,1 & 17 & \\
\hline $\mathrm{Tl}$ & $<0,5$ & & $<0,5$ & $<0,5$ & & $<0,5$ & 3,5 & 1,8 & \\
\hline $\mathrm{Tm}$ & 0,26 & & 0,32 & 0,1 & & 0,12 & 0,36 & 0,34 & \\
\hline$U$ & 2,32 & & 1,92 & 2,37 & & 3,86 & 3,37 & 2,22 & \\
\hline W & 10,3 & & 11,2 & 11,6 & & 16,5 & 17,1 & 22,1 & \\
\hline Y & 17,27 & & 20,37 & 5,74 & & 9,33 & 26,88 & 27,34 & \\
\hline $\mathrm{Yb}$ & 1,7 & & 2 & 0,7 & & 0,8 & 2,2 & 2,2 & \\
\hline
\end{tabular}

LOI: perda na ignição - fornece análises qualitativas e quantitativas das águas cristalinas e dos componentes voláteis das amostras. 
hornblenda quartzo sienito e hornblenda quartzo álcali feldspato sienito, grosso, ligeiramente porfiríticos. Essas rochas contêm megacristais de ortoclásio de até $3 \mathrm{~cm}$ de comprimento, quartzo e plagioclásio (An 3-10) como minerais essenciais, em ordem decrescente de abundância. Hornblenda, que chega a atingir $1 \mathrm{~cm}$, e por vezes biotita são as principais fases máficas desse sienito. Hornblenda apresenta pleocroísmo variando de marrom-claro a verde-azulado e ocasionalmente inclusões de magnetita e zircão. Titanita euédrica, que chega a atingir $1 \mathrm{~mm}$, epídoto magmático, zircão, apatita e magnetitas euédrica $(\sim 0,5 \mathrm{~mm})$ e anédrica formam a mineralogia acessória. É comum a ocorrência de agregados de hornblenda + biotita + titanita + magnetita + epídoto, além de enclaves dioríticos (Figura 3A). Estes são ricos em anfibólio, possuem contornos arredondados e variam no comprimento de 3 a $20 \mathrm{~cm}$. Essa unidade se distingue petrograficamente pela maior quantidade de feldspato potássico e granulação grossa, com cristais grandes de anfibólio e magnetita.

O Plúton Maravilha (Figuras 2 e 4) possui cerca de $200 \mathrm{~km}^{2}$ e é constituído de monzogranito de granulação média, porfirítico, com megacristais de ortoclásio de até $5 \mathrm{~cm}$ de comprimento. A associação mineral é composta, além de ortoclásio, plagioclásio (An 23-27) e quartzo, de biotita e, menos comumente, anfibólio. Os minerais acessórios presentes são: epídoto magmático zonado, com núcleo

Tabela 5. Resumo dos dados de zircão U-Pb (Sensitive High Resolution Ion Micro Probe - SHRIMP) para as amostras $\mathrm{CH}-03$ e $\mathrm{CH}-17$.

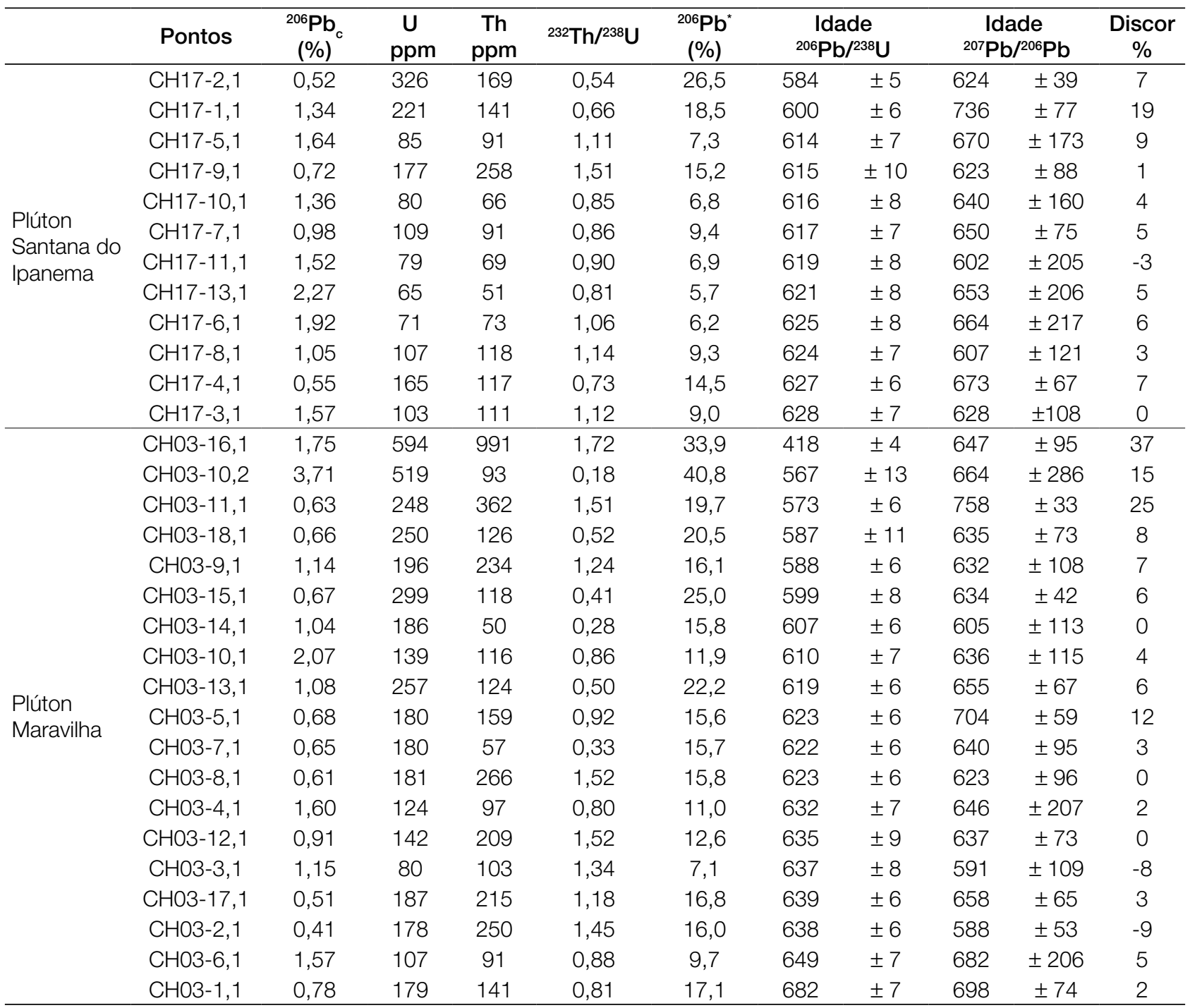

Pppm: partes por milhão; Discor.; Área do erro 1-sigma; *indicam as porções comum e radiogênica, respectivamente.

$\mathrm{Pb}$ comum corrigido usando ${ }^{204} \mathrm{~Pb}$ medidos. 
de allanita, na borda de biotita (Figura 4B), equivalente ao tipo 2 proposto por Sial (1990); titanitas euédricas $(\sim 2 \mathrm{~mm})$ e magnetitas. A principal característica desse granito é uma forte foliação magmática, de direção NW-SE.

O Plúton Santana do Ipanema $\left(290 \mathrm{~km}^{2}\right)$ consiste em monzogranito a sienogranito (Figuras 2 e 5), equigranulares, que é a principal feição que o distingue das outras intrusões estudadas, e possui uma suave orientação magmática na direção WNW-ESE. A assembleia mineral essencial é composta

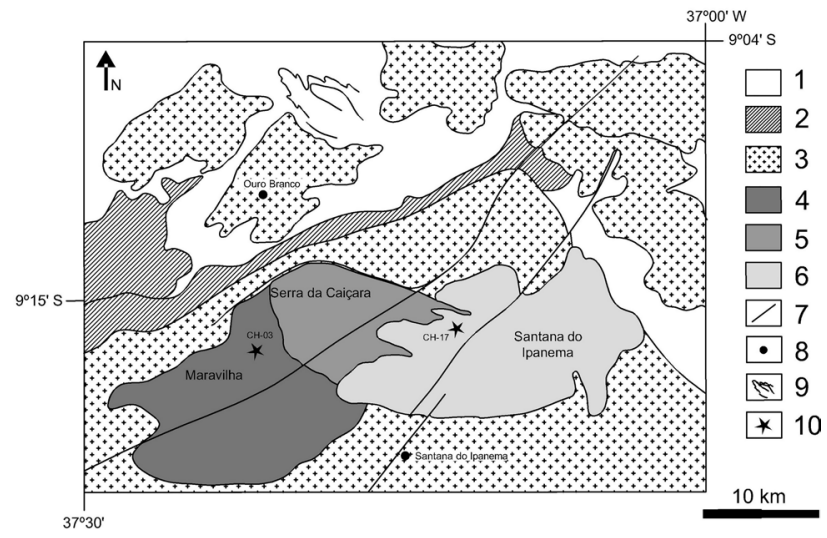

1: rochas metassedimentares do Complexo Cabrobó; 2: ortognaisses do Complexo Belém do São Francisco; 3: outros granitoides Brasilianos; 4: Plúton Maravilha (monzogranito porfiríticos); 5: Plúton Serra da Caiçara (hornblenda quartzo sienito e hornblenda quartzo álcali feldspato sienito); 6: Plúton Santana do Ipanema (sienogranitos a monzogranitos, equigranulares); 7: falhas transcorrentes ou zonas de cisalhamento; 8: cidades; 9: dobramentos no Complexo Cabrobó; 10: localização das amostras datadas por U-Pb (SHRIMP).

Figura 2. Mapa geológico simplificado da área de estudo, enfatizando os Plútons Maravilha, Serra da Caiçara e Santana do Ipanema. de ortoclásio, plagioclásio e quartzo. Hornblenda $(4 \mathrm{~mm})$ e biotita $(3 \mathrm{~mm})$ são as principais fases máficas. O anfibólio é similar ao encontrado no sienito Serra da Caiçara, de pleocroísmo marrom-claro a verde-azulado, ocorrendo, por vezes, geminado. Titanita (euédrica), magnetita, epídoto e zircão também estão presentes como minerais acessórios. É comum a presença de agregados de $3 \mathrm{~cm}$ de biotita e anfibólio (Figura 5A). Além do caráter equigranular, essa unidade se distingue das outras duas trabalhadas por apresentar, aproximadamente, as mesmas quantidades de biotita e anfibólio.

\section{QUÍMICA MINERAL}

\section{Biotita}

Foram analisados centro e borda de cristais de biotita dos Granitos Santana do Ipanema (um cristal) e Maravilha (dois cristais). Os dados são apresentados na Tabela 1. Não foram analisados cristais de biotita para o Plúton Serra da Caiçara.

A química de biotita pode dar informações sobre sua natureza ígnea primária, de acordo com o proposto por Nachit et al. (1985). Nos diagramas da Figura 6A, as composições dos cristais de biotita do Plúton Maravilha caem na transição entre os campos das biotitas primária e primária equilibrada. Já as amostras do Plúton Santana do Ipanema estão inseridas no campo das biotitas primárias reequilibradas, porém próximo ao limite com o campo das primárias. O equilíbrio pode estar associado a um equilíbrio em estágio magmático tardio, associado à deformação regional. O conteúdo $\mathrm{Fe} \#[\mathrm{Fe} /(\mathrm{Fe}+\mathrm{Mg})]$ nas biotitas é intermediário, variando entre 0,49 e 0,52 no
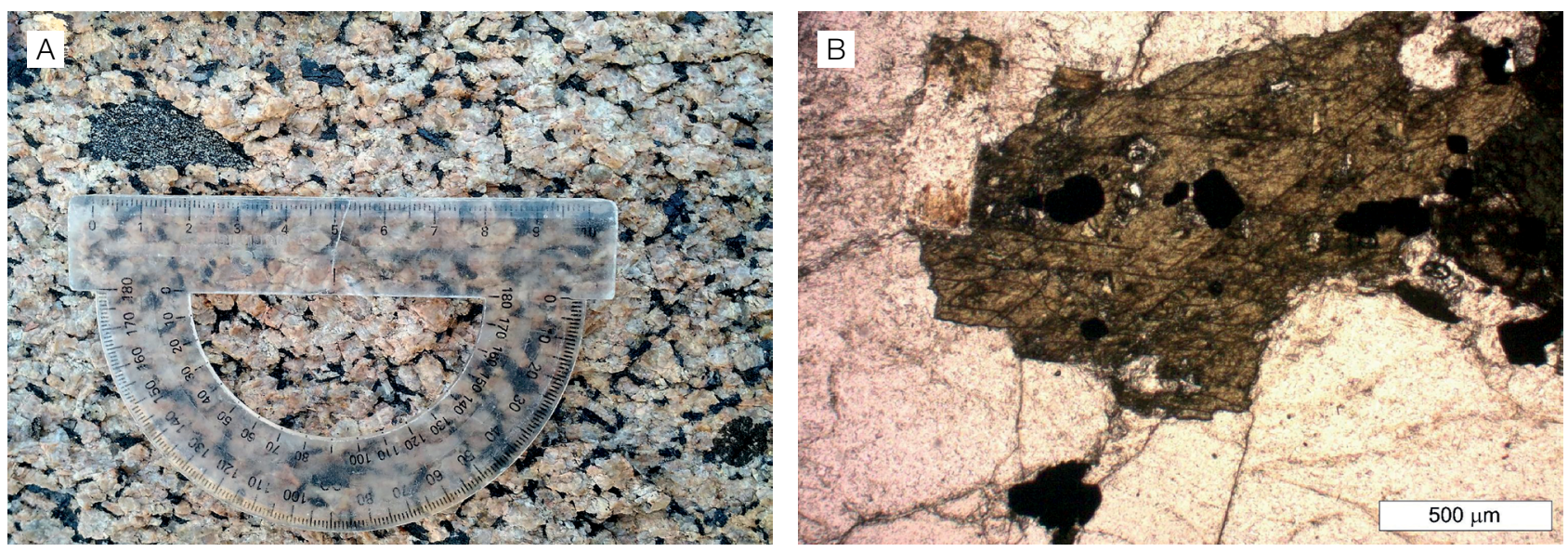

Figura 3. (A) Plúton Serra da Caiçara, hornblenda quartzo sienito, mostrando o tamanho dos grãos de anfibólio e presença de pequenos enclaves dioríticos, ricos em anfibólio. (B) Fotomicrografia de anfibólio do Plúton Serra da Caiçara apresentando inclusões de magnetita (polarizadores em paralelo). 
Plúton Maravilha, sendo mais baixo - 0,43 — no Plúton Santana do Ipanema (Figura 6B). Os cristais de biotita mostram composição semelhante às de biotita de granitos da série subalcalina (Santana do Ipanema) e cálcio-alcalina (Maravilha), de acordo com a classificação proposta por Nachit et al. (1985), utilizando os teores de Mg e Al total (Figura 6C). Isso é confirmado usando os teores de $\mathrm{FeOt}$, $\mathrm{MgO}$ e $\mathrm{Al}_{2} \mathrm{O}_{3}$, que são semelhantes àqueles em biotita de granitos cálcio-alcalinos, de acordo com Abdel-Rahman (1994) (Figuras 6D, 6E e 6F).

\section{Anfibólio}

Análises químicas foram feitas em seis cristais de anfibólio, totalizando 12 exames, ao considerar borda e centro analisados em cada cristal. Cada plúton (Maravilha, Santana do Ipanema e Serra da Caiçara) teve dois cristais analisados. Os resultados são apresentados na Tabela 2.

A classificação proposta por Leake et al. (1997), utilizada para os anfibólios que possuem $\mathrm{Ca}>1,50 \mathrm{e}$ $(\mathrm{Na}+\mathrm{K})_{\mathrm{A}}<0,50$, permitiu classificar os grãos analisados
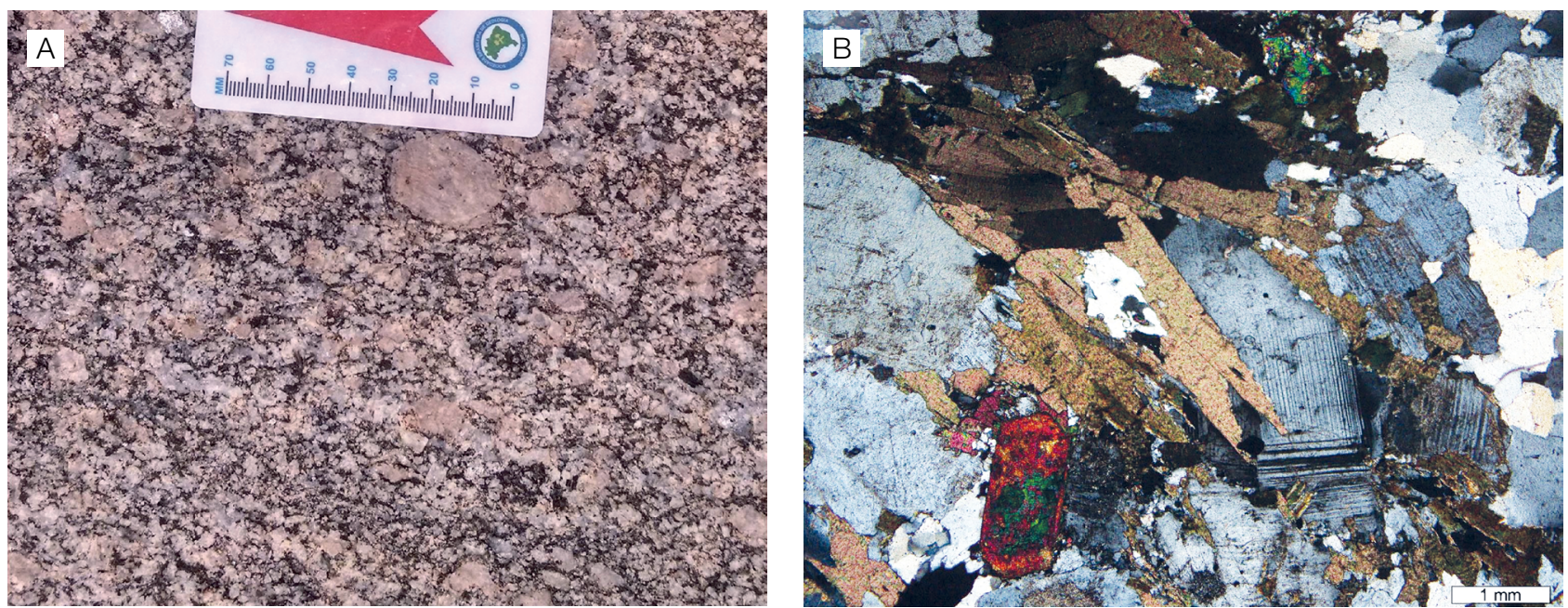

Figura 4. (A) Monzogranito Maravilha com granulação media inequigranular. (B) Fotomicrografia do monzogranito mostrando orientação de palhetas de biotitas, formando uma trama S-C incipiente, e epídoto magmático com núcleo de alanita (polarizadores cruzados).
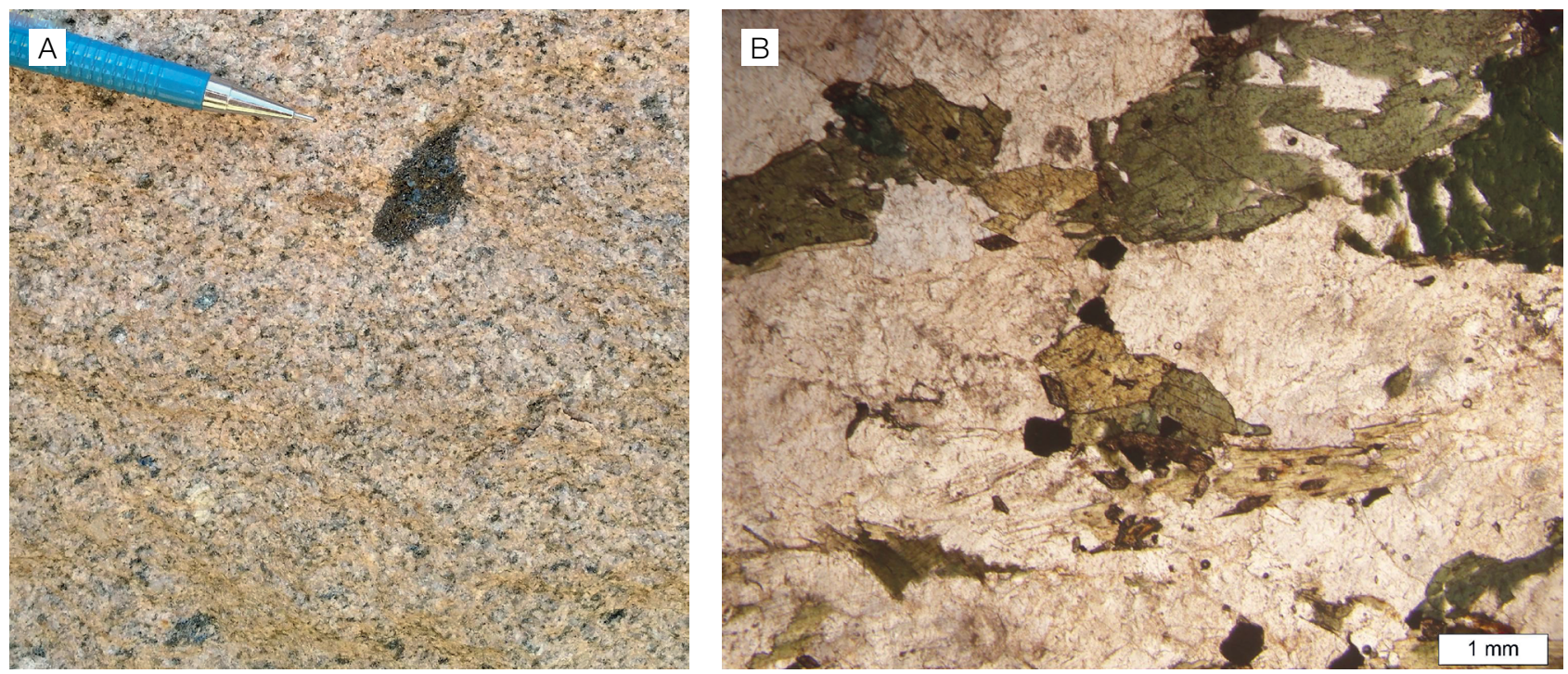

Figura 5. (A) Monzogranito a sienogranito Santana do Ipanema, mostrando sua textura equigranular, e biotita e anfibólio definindo uma foliação magmática. (B) Fotomicrografia do monzogranito mostrando agregados com titanita euédrica, anfibólio, biotita e magnetitas euédrica a subédrica (polarizadores em paralelo). 
A

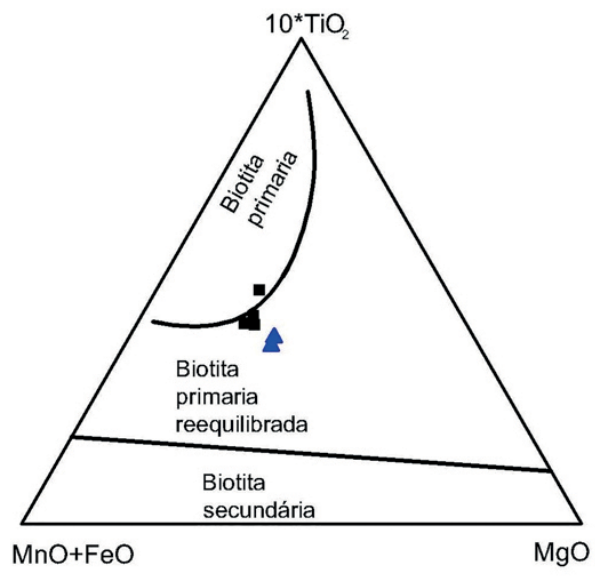

C

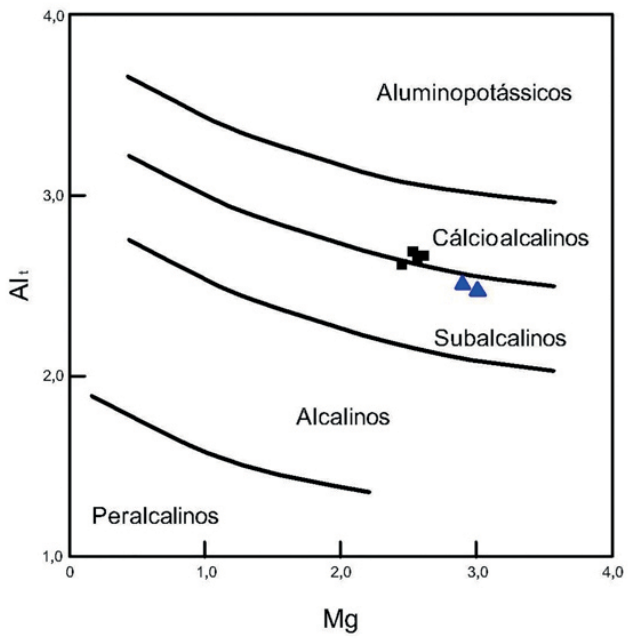

E

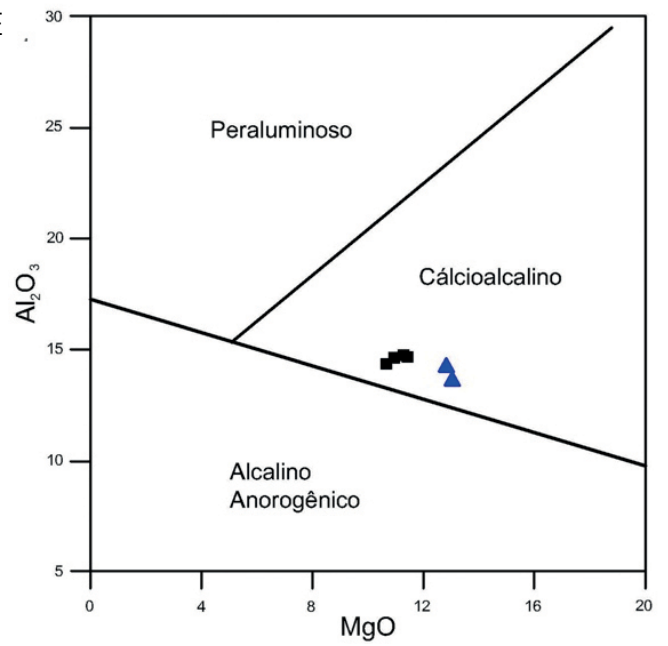

B

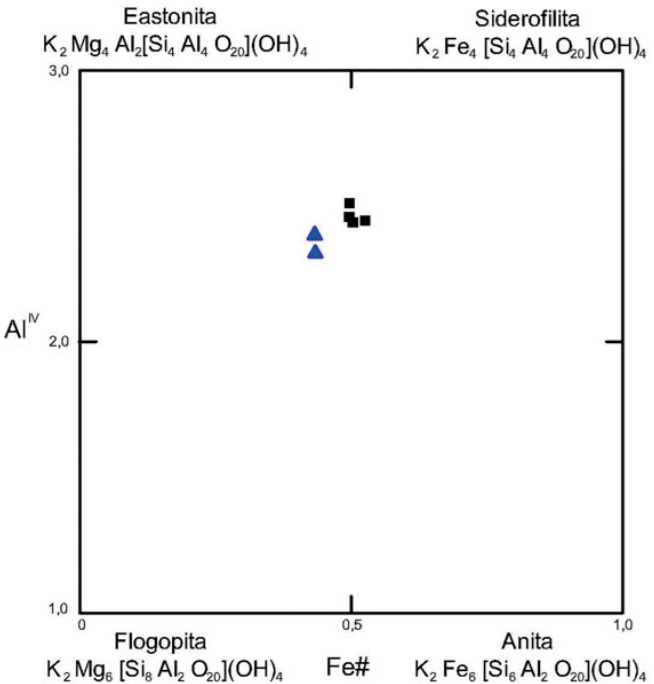

D

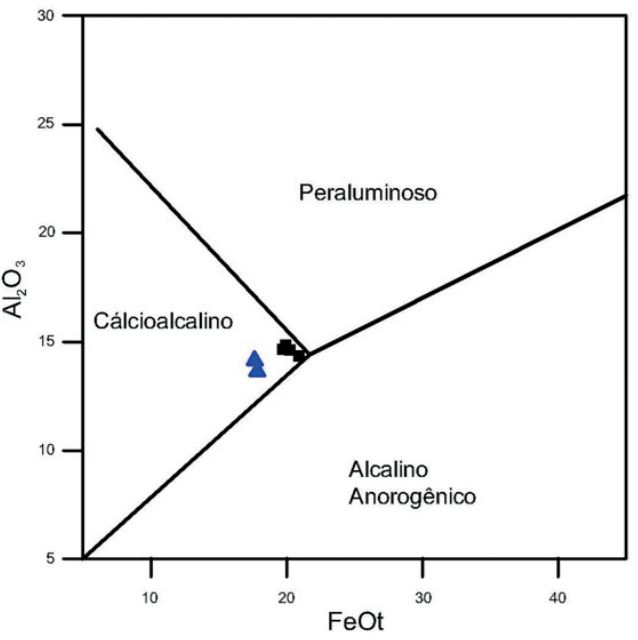

$\mathrm{F}$

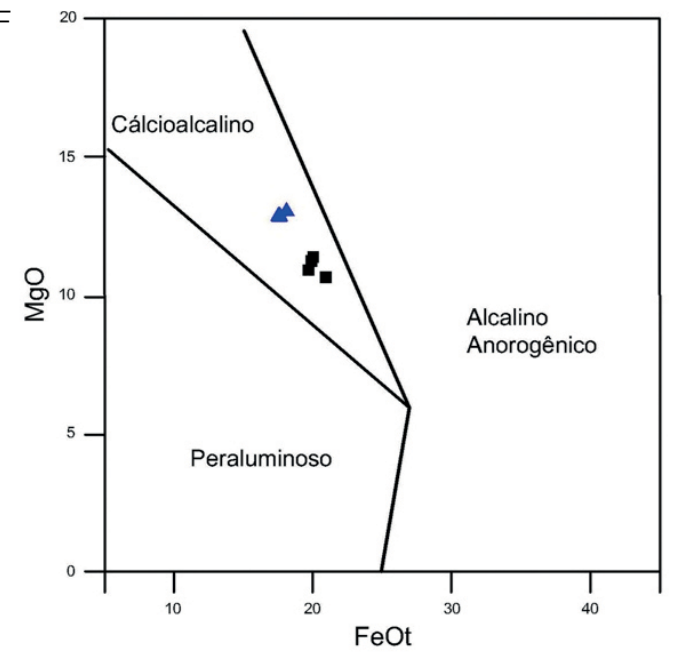

Triângulos azuis referentes ao Plúton Santana do Ipanema, quadrados pretos referentes ao Plúton Maravilha.

Figura 6. Diagramas químicos para a classificação de cristais de biotita de acordo com o ambiente tectônico dos granitos onde ocorrem. (A) Diagrama ternário $\mathrm{MgO} \times 10 \mathrm{TiO}_{2} \times \mathrm{MnO}+\mathrm{FeO}$ (Nachit et al., 1985) para os cristais de biotita estudados. (B) Diagrama Fe\# $\times$ Allv. (C) Diagrama Mg $\times$ Alt de Nachit et al. (1985). (D, E e F) Digramas de Abdel-Rahman (1994). 
como magnésio-hornblenda, para os cristais dos Plútons Serra da Caiçara e Santana do Ipanema, e como tschermakita a ferro-tschermakita, para os cristais do Plúton Maravilha (Figura 7A). O conteúdo de Fe\# varia de 0,49 a 0,53 nos cristais do Sienito Serra da Caiçara, de 0,47 a 0,54 nos cristais do Granito Santana do Ipanema e são mais altos, de 0,56 a 0,67 , nos cristais do Granito Maravilha. Correlacionando os valores de $\mathrm{Fe} \# \mathrm{x} \mathrm{Al}^{\mathrm{IV}}$ e aplicando diagrama de Anderson e Smith (1995), que apresenta os campos para fugacidade de oxigênio, fica claro que os anfibólios dos três plútons foram cristalizados em condições de alta $\mathrm{fO}_{2}$ (Figura 7B), indicando um ambiente oxidante. Os cristais de anfibólio dos três plútons mostram composição típica de anfibólios magmáticos, segundo Czamanske e Wones (1973) (Figura 7C).

\section{Plagioclásio}

Foram analisados quatro cristais de plagioclásio — dois do Plúton Maravilha e dois do Serra da Caiçara - , totalizando oito análises de núcleo e borda. Os dados são apresentados na Tabela 3. Não foram analisados cristais de plagioclásio no Plúton Santana do Ipanema.
A

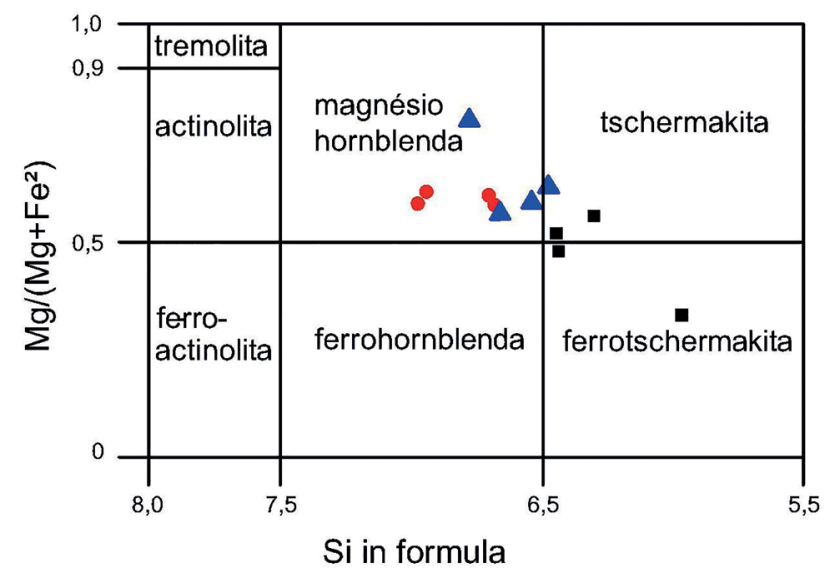

C

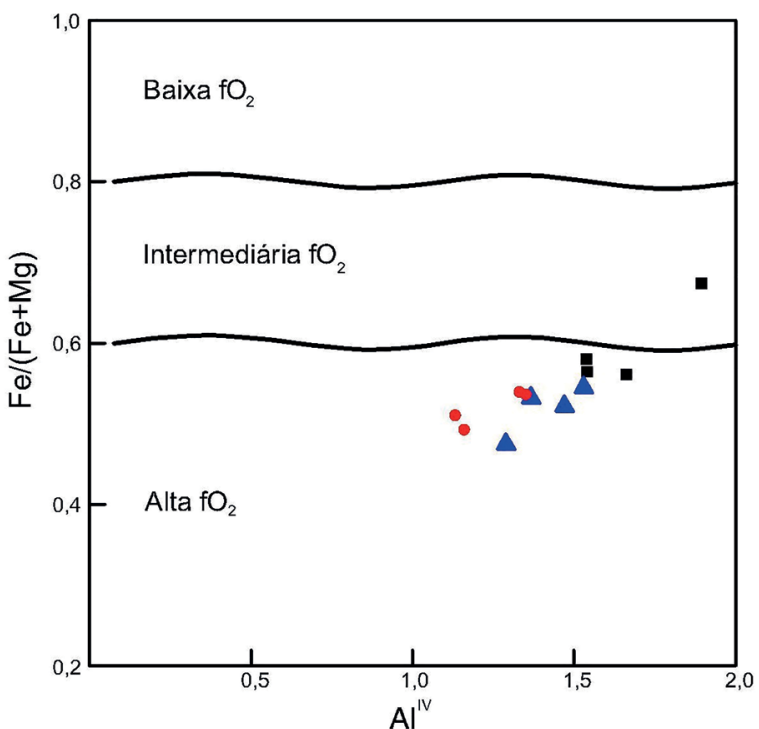

$\mathrm{B}$

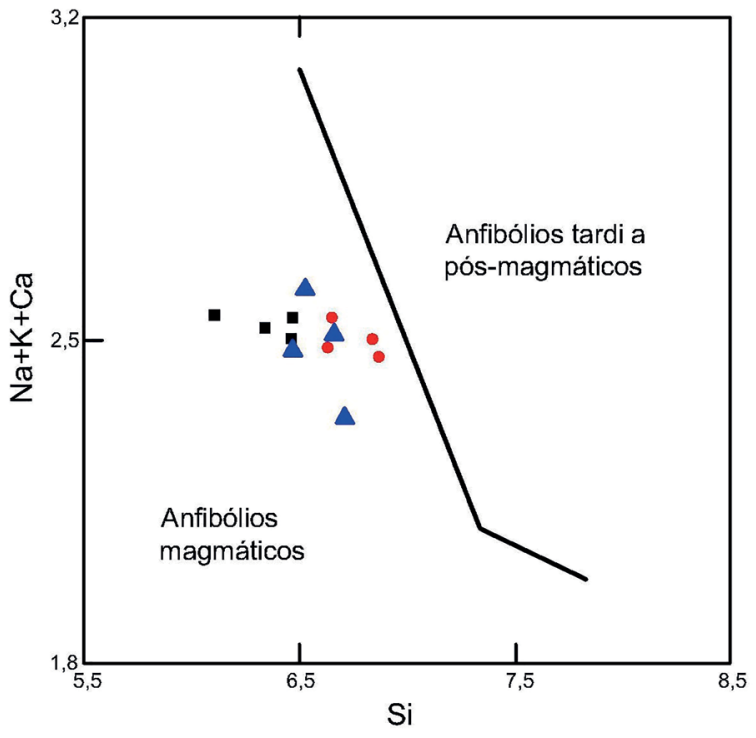

D

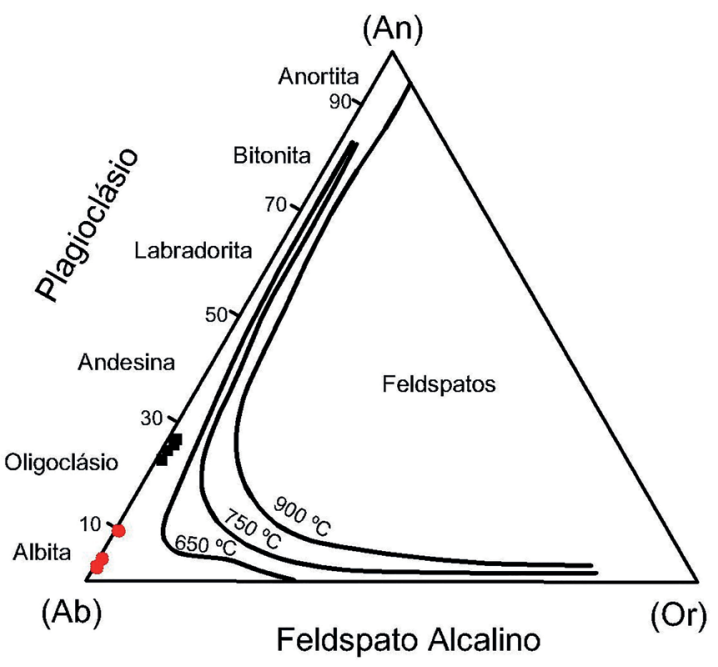

Quadrados pretos referentes ao Plúton Maravilha, triângulos azuis referentes ao Plúton Santana do Ipanema e bolas vermelhas referentes ao Plúton Serra da Caiçara. Figura 7. Diagramas químicos para classificação de anfibólios. (A) Diagramas para classificação de cristais de anfibólios de Leake et al. (1997). (B) Diagrama Silv $\times(\mathrm{Na}+\mathrm{K}+\mathrm{Ca}$ ) com os campos de Czamanske e Wones (1973). (C) Diagrama Alv $\times \mathrm{Fe} /(\mathrm{Fe}+\mathrm{Mg})$, com os campos de $\mathrm{fO}_{2}$ segundo Anderson e Smith (1995). (D) Diagrama ternário An-Ab-Or para classificação dos feldspatos estudados (modificado de Deer et al., 1992). 
De acordo com as proporções An-Ab-Or e utilizando o diagrama de classificação de feldspatos de Deer et al. (1992), é possível classificar os plagioclásios do Plúton Maravilha como oligoclásio (An 23-27) e os do Serra da Caiçara como albita (An 3-10) (Figura 7D). O plagioclásio mais sódico do Plúton Serra de Caiçara confirma seu caráter mais diferenciado em relação ao Maravilha.

\section{QUÍMICA DE ROCHA TOTAL}

As intrusões estudadas são constituídas de rochas intermediárias a ácidas, com valores de $\mathrm{SiO}_{2}$ que variam de 62,71 a 70,88\% para o Plúton Maravilha, de 63,94 a 75,60\% no Santana do Ipanema e de 64,92 a 67,29\% no Serra da Caiçara (Tabela 4). Os plútons são caracterizados, de acordo com Maniar e Piccoli (1989), como metaluminosos a fracamente peraluminosos (Figura 8A). De acordo com a classificação de Irvine e Baragar (1971), esses plútons são cálcio-alcalinos (Figura 8B), seguindo uma tendência de variação composicional subparalela ao eixo $\mathrm{A}\left(\mathrm{Na}_{2} \mathrm{O}+\mathrm{K}_{2} \mathrm{O}\right)-\mathrm{F}(\mathrm{FeO})$, refletindo cristalização em condições de alta fugacidade de oxigênio. As rochas estudadas são cálcio-alcalinas de alto potássio a shoshoníticas (Peccerillo e Taylor, 1976), sendo o Sienito Serra da Caiçara preferencialmente shoshonítico e os Granitos Maravilha e Santana do Ipanema preferivelmente cálcio-alcalinos de alto potássio (Figura 8C).
A

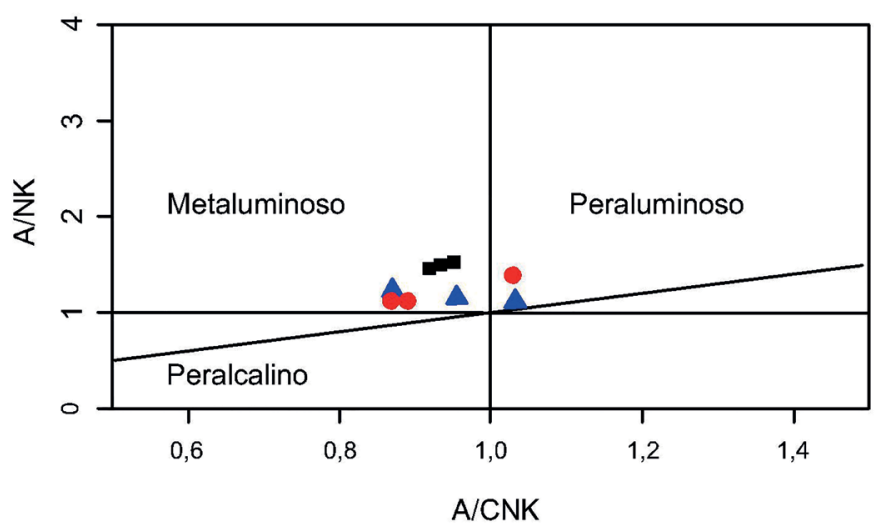

B

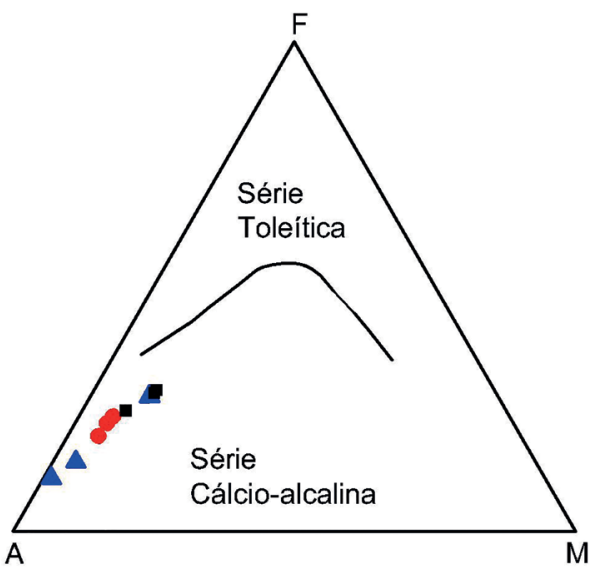

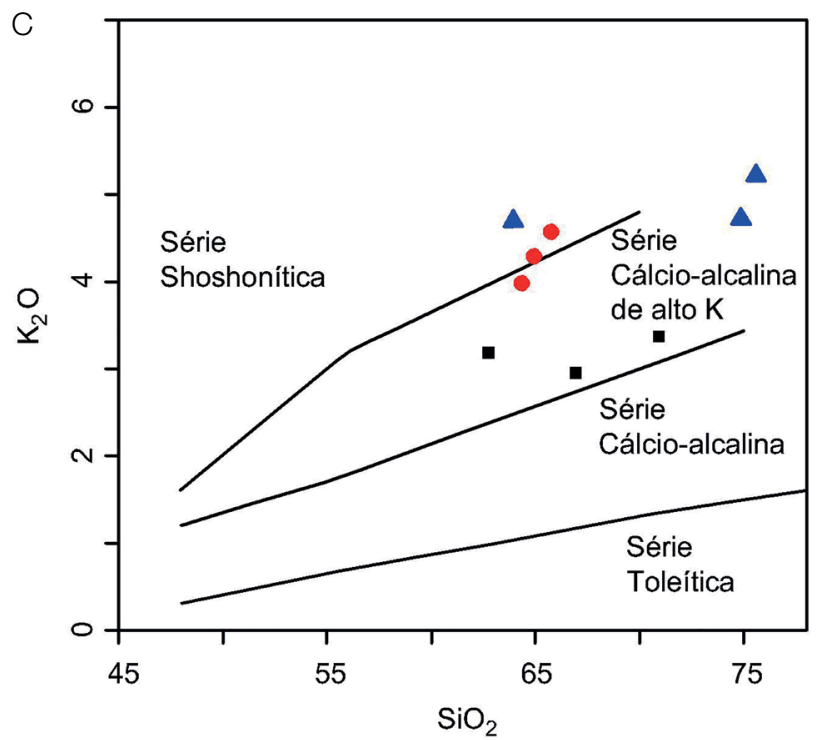

D

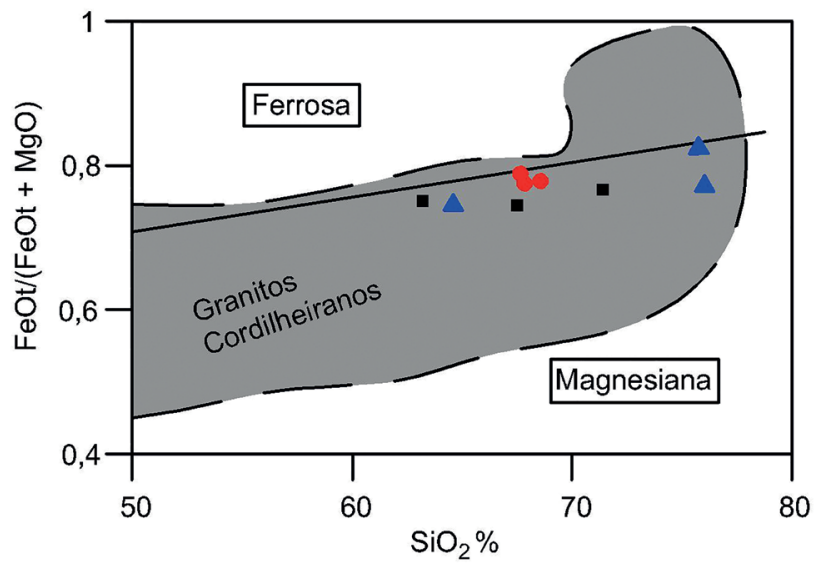

Linha tracejada marca o campo dos Granitos Cordilheiranos. Quadrados pretos referentes ao Plúton Maravilha, triângulos azuis referentes ao Plúton Santana do Ipanema e bolas vermelhas referentes ao Plúton Serra da Caiçara.

Figura 8. Classificação química para os plútons estudados. (A) Diagrama de classificação quanto à saturação de alumina, segundo o índice de Shand. (B) Diagrama ternário AFM de Irvine e Baragar (1971). (C) Diagrama de Peccerillo e Taylor (1976). (D) Diagrama das séries ferrosa e magnesiana de Frost et al. (2001) para as rochas estudadas. 
As rochas analisadas são da série magnesiana, tendo $(\mathrm{FeOt} /(\mathrm{FeOt}+\mathrm{MgO})<0,8$, e plotam no campo de variação composicional para Granitos Cordilheiranos, orogênicos, refletindo magmas hidratados e oxidantes (Frost e Lindsley, 1991; Frost et al., 2001) (Figura 8D).

Os padrões de ETR (Figura 9A) normalizados para valores do condrito de Nakamura (1974) são fracionados, com enriquecimento dos ETR leves em relação aos pesados, e $(\mathrm{La} / \mathrm{Lu})_{\mathrm{N}}$ variando de 18,3 a 19,9 (Plúton Maravilha), 13,6 a 82,2 (Plúton Santana do Ipanema) e 43,3 a 48,3 (Plúton Serra da Caiçara). Esses dados indicam que o Granito Santana do Ipanema é mais fracionado em relação aos outros. Os padrões mostram anomalia de Eu ligeiramente negativa. Embora os padrões sejam semelhantes para as três intrusões, o Sienito Serra da Caiçara apresenta o total de ETR significativamente mais alto que os Granitos Maravilha e Santana do Ipanema (que apresenta o mais baixo valor total de ETR).

Em diagrama multielementar (Figura 9B), normalizado em relação ao condrito com valores sugeridos por Thompson (1982), amostras dos três plútons formam padrões semelhantes. Esses padrões são caracterizados por enriquecimento em elementos litófilos de grande raio iônico (LILE), em relação aos elementos de alto potencial iônico (HFSE), característica comum aos granitoides cálcio-alcalinos fracionados, e por calhas em Nb, Ta, Ti e P.

Os padrões de ETR e diagramas de elementos incompatíveis para os plútons estudados são semelhantes àqueles para outras intrusões do Batólito Águas Belas-Canindé, como no Plúton Major Isidoro (Silva et al., 2015) (Figuras 9B e 9C), que aflora na porção extremo sudeste do Batólito Águas Belas-Canindé. As anomalias negativas em Nb, Ta e Ti em diagramas de elementos incompatíveis são comuns a todos os plútons considerados. Os Plútons Serra da Caiçara,

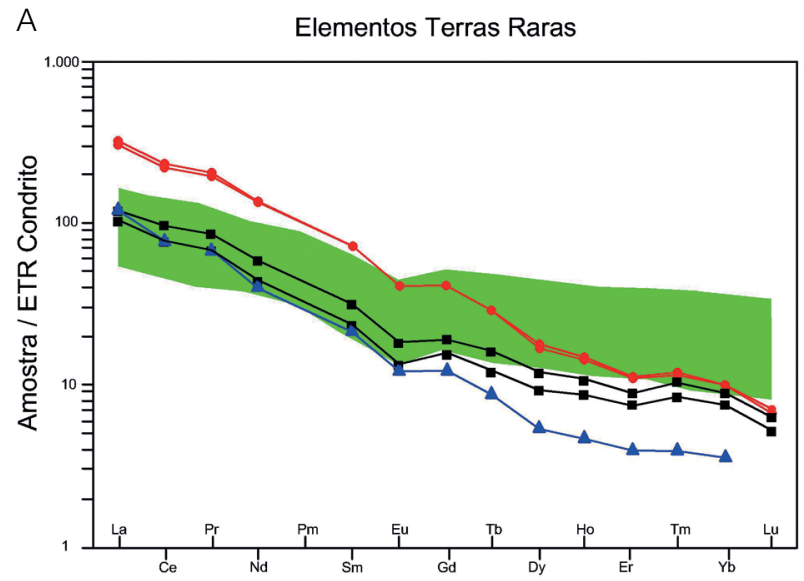

Santana do Ipanema e Maravilha mostram padrões de ETR mais inclinados que os descritos pelo Plúton Major Isidoro, com anomalias negativas de Eu levemente mais profundas.

Em diagramas de discriminação de ambiente tectônico de Pearce et al. (1984), que sugerem os possíveis ambientes de origem de magmas graníticos, as amostras analisadas caem no campo dos granitos de arco vulcânico (VAG) (Figura 10).

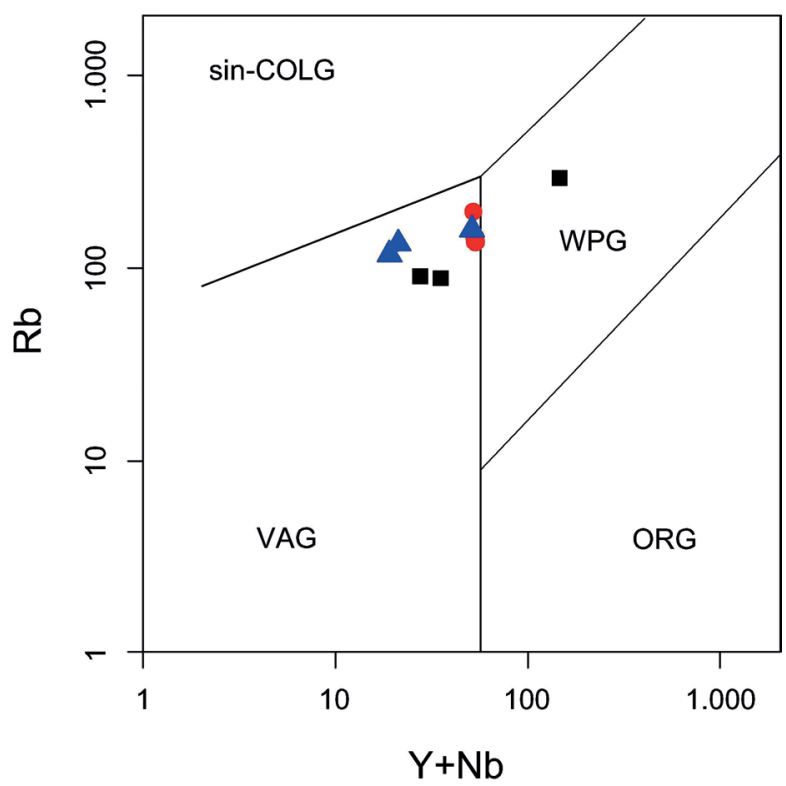

Campos: VAG: granito de arco vulcânico; ORG: granito de cadeia oceânica; WPG: granito intraplaca; syn-COLG: granito sin-colisional. Bolas pretas referentes ao Plúton Maravilha, azuis referentes ao Santana do Ipanema e vermelhas referentes ao Serra da Caiçara.

Figura 10. Diagrama de discriminação tectônica $Y+\mathrm{Nb}$ vs. Rb de Pearce et al. (1984). Os três plútons são caracterizados, preferencialmente, como granito de arco vulcânico.

B

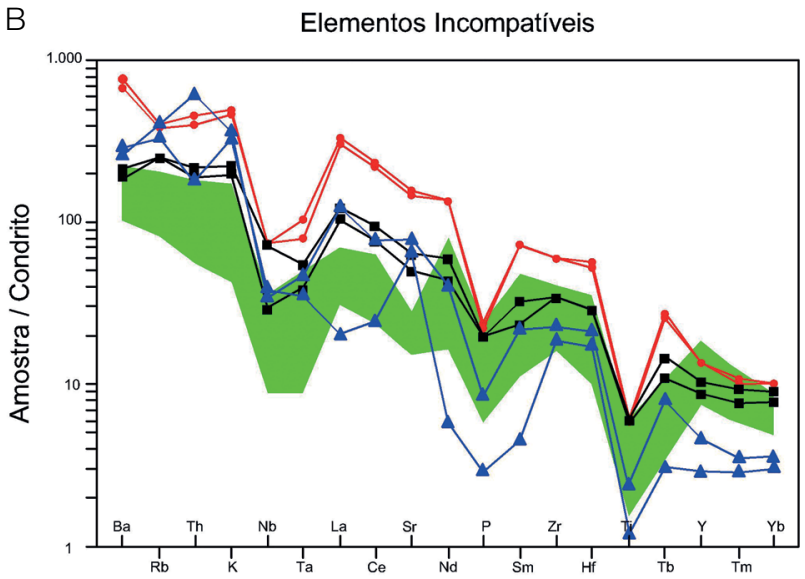

Figura 9. (A) Diagrama de elementos terras raras, normalizado para valores de Nakamura (1974), indicando um padrão moderadamente a altamente fracionado. (B) Diagrama de elementos incompatíveis, normalizado para valores de Thompson (1982), indicando anomalias negativas de Nb, Ta, TI e P. Campos com a média dos padrões elementos terras raras (A) e elementos incompatíveis (B) do Plúton Major Isidoro (Silva et al., 2015). 


\section{CONDIÇÕES DE CRISTALIZAÇÃO}

Para obter as condições de pressão, temperatura e fugacidade de oxigênio dos Magmas Serra da Caiçara, Santana do Ipanema e Maravilha, foram utilizados os dados de química mineral.

\section{Fugacidade de oxigênio}

De acordo com Abbott e Clarke (1979) e Abott (1985), a fugacidade de oxigênio é um importante controle dos minerais que serão formados em rochas ígneas. Desse modo, os conteúdos intermediários de Fe\# em biotita e anfibólio indicam condições de alta fugacidade de oxigênio de acordo com os critérios de Anderson e Smith (1995) (Figura 7C). Essa conclusão é sustentada pela presença nas rochas estudadas de anfibólios ricos em $\mathrm{Mg}$, biotitas de cristalização precoce, titanita euédrica, magnetita e epídoto magmático, enfatizando as condições oxidantes. Por outro lado, a presença da assembleia mineral quartzo + titanita + magnetita, presente nos três plútons, segundo Wones (1989), implica uma fugacidade acima do tampão QFM.

Outra característica que embasa a alta fugacidade de oxigênio é a alta susceptibilidade magnética apresentada pelos plútons. O Plúton Maravilha tem essa susceptibilidade, medida em campo, variando de $3,29 \times 10^{-3}$ a $11,9 \times$ $10^{-3} \mathrm{SI}$; o Santana do Ipanema tem variação de $4,32 \times 10^{-3}$ a $15,2 \times 10^{-3} \mathrm{SI}$; e o Serra da Caiçara apresenta uma alteração de $4 \times 10^{-3}$ a $20,8 \times 10^{-3}$. Os três plútons apresentam valores equivalentes aos propostos por Ishihara (1977) para granitos da série Magnetita Granito, que apresentam valores $>3 \times 10^{-3} \mathrm{SI}$.

\section{Temperatura}

A equação de Watson e Harrison (1983) foi utilizada para estimar as temperaturas de saturação de zircônio, que leva em consideração o conteúdo de $\mathrm{Zr}$ em rocha total. Como o zircão é uma das fases mais precoces na cristalização do magma, as temperaturas obtidas podem ser interpretadas como a temperatura mínima do liquidus. As temperaturas obtidas para os plútons estudados foram de 819 a $826^{\circ} \mathrm{C}$ (Plúton Maravilha), 810 a $889^{\circ} \mathrm{C}$ (Plúton Santana do Ipanema) e 782 a $892^{\circ} \mathrm{C}$ (Plúton Serra da Caiçara). Esses valores são razoáveis para magmas intermediários a ácidos e podem ser considerados como as temperaturas próximas ao liquidus.

O Granito Maravilha atende às especificações propostas para utilização do termômetro anfibólio-plagioclásio de Holland e Blundy (1994), que leva em conta o teor de $\mathrm{Al}^{\mathrm{IV}}$ em hornblenda e albita no plagioclásio. Para aplicação do método, os cristais de anfibólio devem ter $\mathrm{Si}<7,8 \mathrm{pfu}$ (números de átomos por fórmula) e plagioclásio com conteúdo de $\mathrm{An}<92 \%$, sendo calibrado para temperatura entre 500 e $1.100^{\circ} \mathrm{C}$. Utilizando esse geotermômetro, as temperaturas para o Magma Maravilha variaram de 744 a $766^{\circ} \mathrm{C}$, sendo esses valores de temperatura menores que os obtidos pelo geotermômetro de saturação em $\mathrm{Zr}$, possibilitando serem interpretados como referentes à temperatura de cristalização do anfibólio. O Plúton Santana do Ipanema, por não ter cristais de plagioclásio analisados, e o Plúton Serra da Caiçara, por não atender às especificações necessárias para aplicação do método, não permitiram a utilização do cálculo de temperatura proposto por Holland e Blundy (1994).

\section{Pressão}

A equação de Schmidt (1992) para se estimar pressão de solidificação baseia-se em $\mathrm{Al}^{\mathrm{T}}$ em anfibólio. Aplicando esse geobarômetro, as pressões foram de 3,3 a 4,2 kbar (Plúton Serra da Caiçara), 3,1 a 4,7 kbar (Plúton Santana do Ipanema) e 5,3 a 7,8 kbar (Plúton Maravilha).

O Plúton Maravilha, entre os três estudados, foi o único que possuía análises de plagioclásio + anfibólio e atendia às condições para aplicação do termômetro de Holland e Blundy (1994). Assim, possibilitou o cálculo da pressão por Anderson e Smith (1995), que leva em consideração a temperatura. As pressões calculadas nessa fórmula, utilizando as temperaturas obtidas em Holland e Blundy (1994), foram de 4,4 a 6,3 kbar. Esses valores se aproximam daqueles obtidos usando a equação de Schmidt (1992), são compatíveis com a presença de epídoto magmático e confirmam nível crustal profundo de solidificação do Granito Maravilha.

\section{GEOCRONOLOGIA}

Neste trabalho, foram realizadas datações nos Plútons Santana do Ipanema e Maravilha. Uma datação U-Pb em zircão indica idade $616 \pm 3 \mathrm{Ma}$ para o Sienito Serra da Caiçara, interpretada como idade de cristalização (Mendes et al., 2009).

Foram analisados 19 cristais de zircão para uma amostra extraída do Plúton Maravilha (Tabela 5). Esses grãos são subédricos a euédricos, apresentam zoneamento ígneo típico e mostram alguns pequenos núcleos herdados. O diagrama concórdia U-Pb (Figura 11) mostra a linha concórdia calibrada em Ma. A maioria dos pontos analisados projetou-se próximo à curva concórdia (Figura 11), definindo, dessa forma, uma idade concórdia de 626,5 \pm 5,4 Ma (MSWD $=0,26$ ), que pode ser interpretada como a idade de cristalização. A análise do grão 16.1 produziu uma idade discordante de $421 \pm 4,3 \mathrm{Ma}$. Algumas análises produziram um intercepto superior de $667 \pm 32 \mathrm{Ma}(\mathrm{MSWD}=0,74)$, interpretada como produzida por zircão herdado.

No Granito Santana do Ipanema, foram analisados 12 cristais de zircão (Tabela 5). Os grãos de zircões são subédricos 
a euédricos, apresentam zoneamento ígneo típico e mostram alguns pequenos núcleos herdados. A maioria dos pontos analisados se projetou próximo à curva concórdia, no diagrama concórdia U-Pb (Figura 12), definindo, dessa forma, uma idade concórdia de $621,1 \pm 4,8 \mathrm{Ma}(\mathrm{MSWD}=0,46)$, interpretada como a idade de cristalização. Alguns cristais produziram um intercepto superior de $645 \pm 48 \mathrm{Ma}$ (MSWD $=0,19)$, também interpretado como produzido

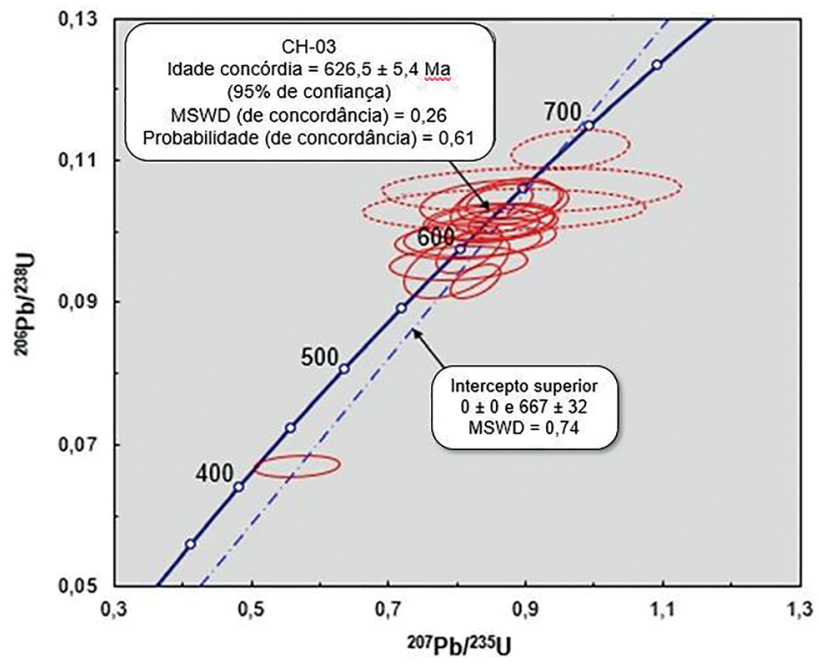

MSWD: Mean Squares of the Weighted Deviated.

Figura 11. Diagrama concórdia U-Pb (Sensitive High Resolution Ion Micro Probe - SHRIMP) para amostra $\mathrm{CH}-03$ do Plúton Maravilha.

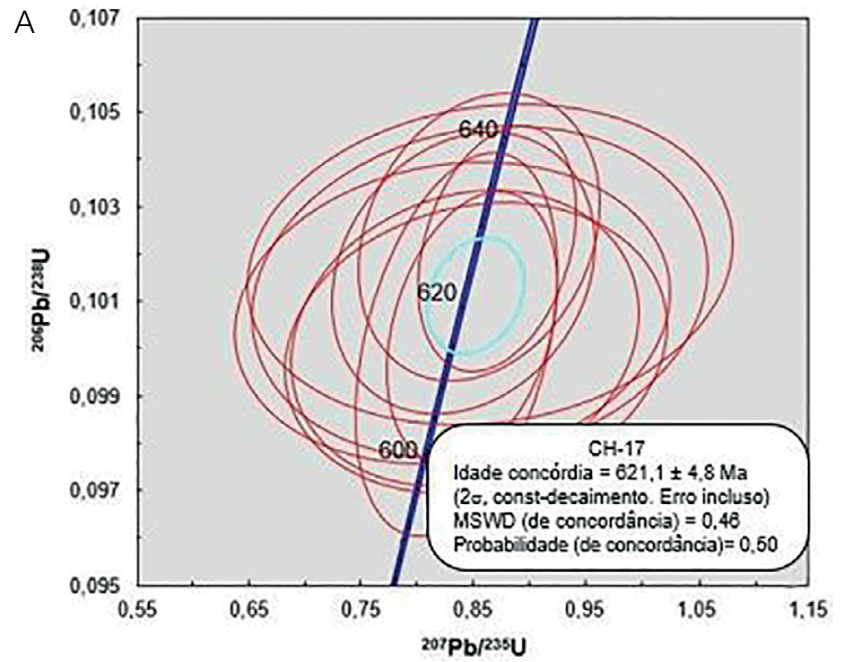

MSWD: Mean Squares of the Weighted Deviated.

Figura 12. Diagrama concórdia U-Pb (Sensitive High Resolution Ion Micro Probe - SHRIMP) para amostra CH-17 do Plúton Santana do Ipanema. (A) Idade concórdia. (B) Intercepto superior. por zircões herdados. As idades de cristalização obtidas confirmam as relações de campo que indicam que o Plúton Maravilha é o mais antigo.

\section{DISCUSSÃO}

Petrograficamente, as rochas distinguem-se por serem porfiríticas (Granito Maravilha), equigranulares (Granito Santana do Ipanema) e ricas em feldspato potássico e hornblenda (Sienito Serra da Caiçara). Quimicamente esses plútons são similares; são rochas metaluminosas a levemente peraluminosas, apesar de a mineralogia presente ser tipicamente metaluminosa (biotita + hornblenda), podendo o caráter peraluminoso estar associado à forte diferenciação do magma (Maniar e Piccoli, 1989) ou ao fracionamento de anfibólios (Barbarin, 1999). As rochas são cálcio-alcalinas de alto K a shoshoníticas, corroboradas pela química de anfibólios e biotitas, que apresentam Fe\# semelhantes ao presente em rocha total $(\mathrm{Fe} \# \sim 0,5)$. Padrões ETR e de elementos incompatíveis sugerem fracionamento de plagioclásio e apatita respectivamente.

As idades de cristalização dos Plútons Serra da Caiçara $616 \pm 3 \mathrm{Ma}$ (Mendes et al., 2009) —, Santana do Ipanema $621,1 \pm 4,8 \mathrm{Ma}$ - e Maravilha - 626,5 $\pm 5,4 \mathrm{Ma}$ - indicam que suas intrusões ocorreram na fase inicial do período de formação da foliação de baixo ângulo, no Orógeno Brasiliano. Esse fato justifica a ocorrência de estruturas como linhas de estiramento mineral na direção NW-SE, bandas de cisalhamento e trama S-C nos corpos estudados. O intercepto superior produzido pelo Plúton Maravilha — $667 \pm 32 \mathrm{Ma}$ —é uma

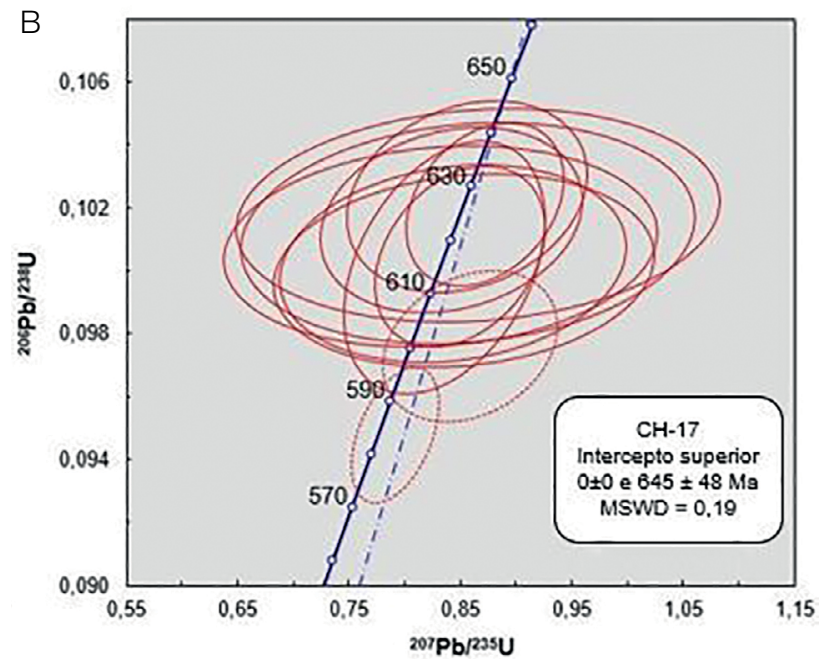


idade relacionada a algum evento não identificado. Já o intercepto produzido pelo Plúton Santana do Ipanema $645 \pm 48 \mathrm{Ma}$ - se aproxima dos valores obtidos para o período de ativação da Zona de Cisalhamento Transpressional Jacaré dos Homens - $642 \pm 3 \mathrm{Ma}$, idade U-Pb em zircão (SHRIMP) obtida em orto-gnaisse alojado nessa zona (Lima, 2013). Também se aproxima da idade de metamorfismo de orto-gnaisses granulíticos da Sequência Venturosa $642 \pm 15 \mathrm{Ma}$ (U-Pb em zircão, TIMS) (Osako et al., 2006) e indica uma possível herança dos zircões dessas rochas nos plútons estudados. Os Plútons Serra da Caiçara, Santana do Ipanema e Maravilha apresentam similaridades químicas e cronológicas com outros plútons do Batólito Águas Belas-Canindé, como o Major Isidoro (626,6 \pm 3,7 Ma) (Silva et al., 2015), que aflora na porção extremo sudeste do batólito.

As rochas estudadas possuem assinaturas típicas de granitos de arco, com anomalias negativas de $\mathrm{Nb}$ - $\mathrm{Ta}$ (Pearce et al., 1984), e são classificadas como granitos magnesianos ligados à subducção (Frost et al., 2001). O magmatismo cálcio-alcalino de alto $\mathrm{K}$ ocorre amplamente em estágios pós-colisionais (Liégeois et al., 1998; Barbarin, 1999), porém também ocorre em margens continentais ativas (Wilson, 1989; Barbarin, 1999; Condie e Kröner, 2013), possuindo uma relação genética com zonas de subducção (Rogers et al., 1985; Barbarin, 1999). As composições dos plútons estudados, comparadas com aquelas de líquidos obtidos em estudos experimentais de diversas rochas fontes, compilados por Chen et al. (2013), são semelhantes àquelas de rochas basálticas de médio a alto $\mathrm{K}$ (Figuras 13A e 13B), comuns em arcos magmáticos, apoiando assim um ambiente de arco magmático para a intrusão magmática.

O Plúton Major Isidoro (Silva et al., 2015) compartilha das mesmas caraterísticas de magmatismo de arco descritas neste trabalho, sugerindo que a formação do Batólito Águas Belas-Canindé estaria ligada a um arco continental, formado no Domínio Pernambuco-Alagoas, durante a deformação compressional da Orogênese Brasiliana. Neves et al. (2012) sugerem que arcos magmáticos imaturos, resultantes do fechamento de pequenas bacias oceânicas, seriam o ambiente de formação de plútons com essas características.

\section{CONCLUSÃO}

Os Granitos Maravilha (626,5 $\pm 5,4 \mathrm{Ma})$ e Santana do Ipanema $(621,1 \pm 4,8 \mathrm{Ma})$ e o Sienito Serra da Caiçara (616 $\pm 3 \mathrm{Ma}$ ) são rochas cálcio-alcalinas de alto $\mathrm{K}$ que intrudem no Domínio Pernambuco-Alagoas durante a fase inicial da formação da foliação de baixo ângulo, que tem início por volta de $630 \mathrm{Ma}$. Os dados químicos para os Plútons Maravilha, Santana do Ipanema e Serra da Caiçara indicam evolução do magma por cristalização fracionada, em ambiente oxidante. Esses plútons estudados possuem características de magmatismo relacionadas a arco magmático, compartilhadas com outras intrusões graníticas do Batólito Águas Belas-Canindé de idade aproximada. É sugerido, então, que o Batólito Águas Belas-Canindé teve uma evolução ligada à formação de um arco magmático no Domínio Pernambuco-Alagoas.
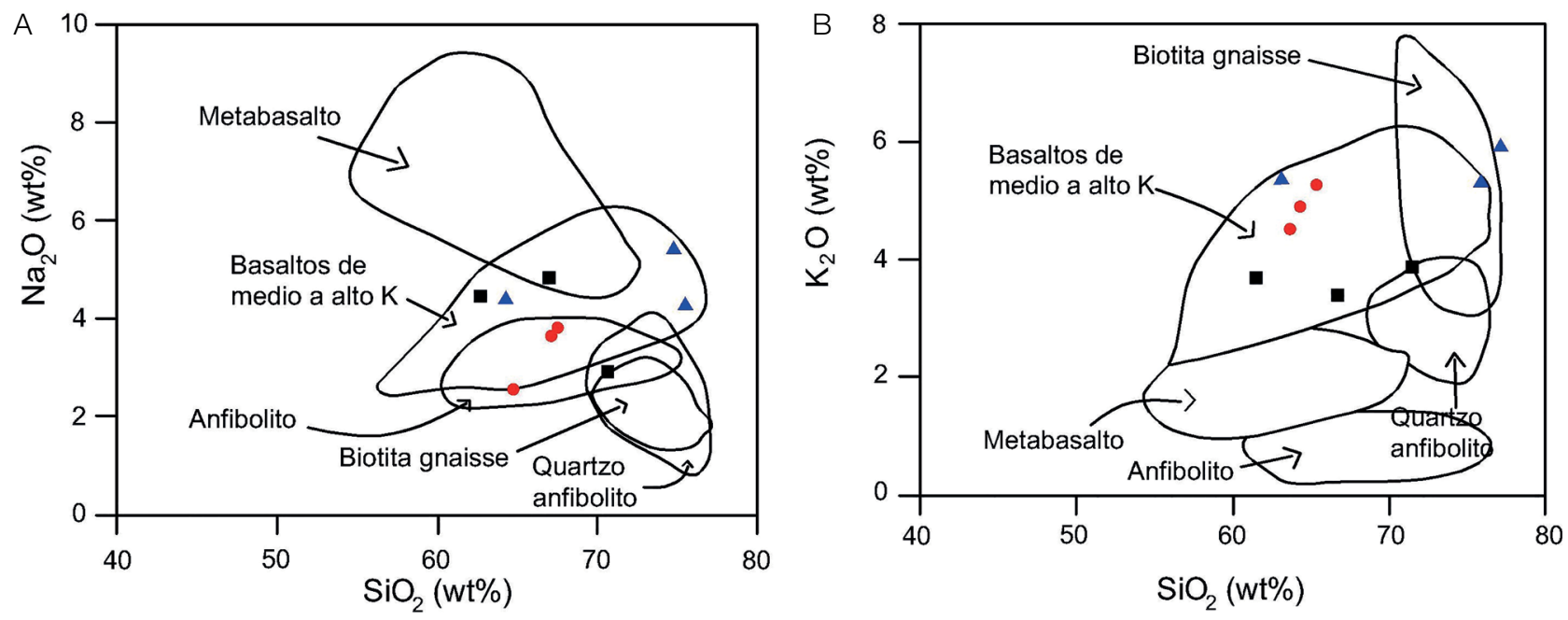

Triângulos azuis referentes ao Plúton Santana do Ipanema, bolas vermelhas, ao Plúton Serra da Caiçara e quadrados pretos, ao Plúton Maravilha.

Figura 13. Diagramas com dados publicados para fusões experimentais, compilados por $\mathrm{Chen} \mathrm{et} \mathrm{al.}(2013)$. $(\mathrm{A}) \mathrm{Na}_{2} \mathrm{O} \times$ $\mathrm{SiO}_{2}$ (B) $\mathrm{K}_{2} \mathrm{O} \times \mathrm{SiO}_{2}$. 


\section{REFERÊNCIAS}

Abbott, J. R. N. (1985). Muscovite-bearing granites in the AFM liquidus projection. Canadian Mineralogist, 23(4), 553-561.

Abbott, J. R. N., Clarke, D. B. (1979). Hypothetical liquidus relationships in the subsystem $\mathrm{Al} 2 \mathrm{O} 3-\mathrm{FeO}-\mathrm{MgO}$ projected from quartz, alkali feldspar and plagioclase for a $(\mathrm{H} 2 \mathrm{O})=$ 1. Canadian Mineralogist, 17, 549-560.

Abdel-Rahman, A. M. (1994). Nature of biotites from alkaline, calc-alkaline, and Peraluminous magmas. Journal of Petrology, 35(2), 525-541. https://doi.org/10.1093/ petrology/35.2.525

Almeida, F. F. M., Hasui, Y., Brito Neves, B. B., Fuck, R. A. (1981). Brazilian structural provinces: An introduction. Earth Science Review, 17(1-2), 1-29. https://doi. org/10.1016/0012-8252(81)90003-9

Anderson, J. L., Smith, D. R. (1995). The effects of temperature and $\mathrm{fO} 2$ on the Al-inhornblende barometer. American Mineralogist, 80(5-6), 549-559. https://doi. org/10.2138/am-1995-5-614

Barbarin, B. (1999). A review of the relationships between granitoid types, their origins and their geodynamic environments. Lithos, 46(3), 605-626. https://doi.org/10.1016/ S0024-4937(98)00085-1

Brito Neves, B. B., Santos, E. J., Van Schmus, W. (2000). Tectonic history of the Borborema province, northeastern Brazil. In: U. Cordani, E. J. Milani, A. Thomaz Filho, D. A. Campos (Eds.), Tectonic evolution of South America. $31^{\text {st }}$ International Geological Congress, p. 151-182. Rio de Janeiro: SBG.

Brito Neves, B. B., Van Schmus, W. R., Santos, E. J., Campos Neto, M. C., Kozuch M. (1995). O Evento Cariris Velhos na Província Borborema: Integração de Dados, Implicações e Perspectivas. Revista Brasileira de Geociências, 25(4), 279-296.

Chen, J. Y., Yang, J. H., Zhang, J. H., Sun, J. F., Wilde, S. A. (2013). Petrogenesis of the Cretaceous Zhangzhou batholith in southeastern China: zircon $\mathrm{U}-\mathrm{Pb}$ age and $\mathrm{Sr}-\mathrm{Nd}-\mathrm{Hf}-\mathrm{O}$ isotopic evidence. Lithos, 162-163, 140-156. https://doi. org/10.1016/j.lithos.2013.01.003

Condie, K. C., Kröner, A. (2013). The building blocks of continental crust: evidence for a major change in the tectonic setting of continental growth at the end of the Archean. Gondwana Research, 23(2), 394-402. https://doi. org/10.1016/j.gr.2011.09.011
Czamanske, G. K., Wones, D. R. (1973). Oxidation during magmatic differentiation: Finnmarka Complex, Oslo Area, Norway. The mafic silicates. Journal of Petrology, 14(3), 349-380. https://doi.org/10.1093/petrology/14.3.349

Deer, W. A., Howie, R. A., Zussman, J. (1992). An introduction to the rock-forming minerals. 2. ed. Nova York: Longman Harlow, 696 p.

Ferreira, V. P., Sial, A. N., Jardim de Sá, E. F. (1998). Geochemical and isotopic signatures of Proterozoic granitoids in terranes of the Borborema structural province, northeastern Brazil. Journal of South American Earth Sciences, 11(5), 439-455. https://doi.org/10.1016/S0895-9811(98)00027-3

Frost, B. R., Barnes, C. G., Collins, W. J., Arculus, R. J., Ellis, D. J., Frost, C. D. (2001). A geochemical classification of granitic rocks. Journal of Petrology, 42(11), 2033-2048. https://doi.org/10.1093/petrology/42.11.2033

Frost, B. R., Lindsley, D. H. (1991). The occurrence of Fe-Ti oxides in igneous rocks. Reviews in Mineralogy and Geochemistry, 25(1), 433-486.

Guimarães, I. P., Da Silva Filho, A. F., Almeida, C. N., Van Schmus, W. R., Araújo, J. M. M., Melo, S. C., Melo, E. B. (2004). Brasiliano (Pan-African) granite magmatism in the Pajeu Pararba belt, Northeast Brazil: An isotopic and geochronological approach. Precambrian Research. 135(1-2), 23-53. https://doi.org/10.1016/j.precamres.2004.07.004

Holland, T., Blundy, J. (1994). Non-ideal interactions in calcic amphiboles and their bearing on amphibole-plagioclase thermometry. Contributions to Mineralogy and Petrology, 116(4), 433-447. https://doi.org/10.1007/BF00310910

Irvine, T. N., Baragar, W. R. A. (1971). A guide to chemical classification of common volcanic rocks. Canadian Journal Earth of Science, 8(5), 523-548. https://doi.org/10.1139/ e71-055

Ishihara, S. (1977). The magnetite-series and ilmenite-series granitic rocks. Mining Geology, 27(145), 293-305. https:// doi.org/10.11456/shigenchishitsu1951.27.293

Jardim de Sá, E. F. (1984). Geologia da região de Seridó: reavaliação de dados. XI Simpósio de Geologia do Nordeste, 278-316. Atas. Natal: SBG - Regional Nordeste.

Jardim de Sá, E. F., Hachspacher, P. C. (1980). Reconhecimento estrutural na borda noroeste do Cráton de São Francisco. XXXI Congresso Brasileiro de Geologia, 5, 2719-2731. Anais. Balneário Camboriú: SBG. 
Jardim de Sá, E. F., Moraes, J. A. C., Silva, L. H. R. (1986). Tectônica tangencial na faixa sergipana. XXXIV Congresso Brasileiro de Geologia, 3, 1246-1249. Anais. Goiânia: SBG.

Leake, B. E., Woolley, A. R., Arps, C. E. S., Birch, W. D., Gilbert, M. C., Grice, J. D., Youzhi, G. (1997). Nomenclature of Amphiboles; Report of the Subcommittee on Amphiboles of the International Mineralogical Association Commission on New Minerals and Mineral Names. Mineralogical Magazine, 61, 295-310. https://doi.org/10.1180/minmag.1997.061.405.13

Liégeois, J. P., Navez, J., Hertogen, J., Black, R. (1998). Contrasting origin of post-collisional high-K calc-alkalic and shoshonitic versus alkalic and peralkalic granitoids. The use of sliding normalization. Lithos, 45(1-4), 1-28. https:// doi.org/10.1016/S0024-4937(98)00023-1

Lima, M. M. C. (2013). Caracterização geoquímica, isotópica e geotectônica dos complexos Araticum e Arapiraca, faixa Sergipana, Alagoas, Nordeste do Brasil. Dissertação (Mestrado). Recife: Universidade Federal de Pernambuco, 89 p.

Maniar, P. D., Piccoli, P. M. (1989). Tectonic discrimination of granitoids. Geological Society of America Bulletin, 101(5), 635-643. https://doi.org/10.1130/0016-7606(1989)101\%3C06 35:TDOG\%3E2.3.CO;2

Medeiros, V. C., Santos, E. J. (1998). Folha Garanhuns (SC.24-X-B, escala 1:250.000). Integração Geológica (Relatório Interno), CPRM. Recife: CPRM.

Mendes, V. A., Brito, M. F. L., Paiva, I. P. (2009). Programa Geologia do Brasil-PGB. Arapiraca. Folha SC.24-X-D. Estados de Alagoas, Pernambuco e Sergipe. Mapa Geológico. Recife: CPRM, 2009. 1 mapa, color, 112,37 × 69,42 cm. Escala: 1:250.000.

Nachit, H., Razafimahefa, N., Stussi, J. M., Carron, J. P. (1985). Composition chimique des biotites et typologie magmatique des granitos. Comptes Rendus de l'Académie des sciences Paris, 301(11), 813-818.

Nakamura, N. (1974). Determination of REE, Ba, Fe, $\mathrm{Mg}, \mathrm{Na}$ and $\mathrm{K}$ in carbonaceous and ordinary chondrites. Geochimica et Cosmochimica Acta, 38(5), 757-775. https:// doi.org/10.1016/0016-7037(74)90149-5

Neves, S. P., Bruguier, O., Bosch, D., Silva, J. M. R., Mariano, G. (2008). U-Pb ages of plutonic and metaplutonic rocks in southern Borborema Province (NE Brazil): timing of Brasiliano deformation and magmatism. Journal of South American Earth Sciences, 25(3), 285-297. https://doi. org/10.1016/j.jsames.2007.06.003
Neves, S. P., Mariano, G., Beltrão, A. B., Correia, P. B. (2005a). Emplacement and deformation of the Cachoeirinha pluton (Borborema province, NE Brazil) inferred trough petrostructural studies: Constraints on regional strain fields. Journal of South American Earth Sciences, 19(2), 127-141. https://doi.org/10.1016/j.jsames.2005.04.004

Neves, S. P., Monié, P., Bruguier, O., Silva, J. M. R. (2012). Geochronological, thermochronological and thermobarometric constraints on deformation, magmatism and thermal regimes in eastern Borborema Province (NE Brazil). Journal of South American Earth Sciences, 38, 129-146. https://doi. org/10.1016/j.jsames.2012.06.003

Neves, S. P., Silva, J. M. R., Mariano, G. (2005b). Oblique lineations in orthogneisses and supracrustal rocks: vertical partitioning of strain in a hot crust (eastern Borborema Province, NE Brazil). Journal of Structural Geology, 27(8), 1513-1527. https://doi.org/10.1016/j.jsg.2005.02.002

Osako, L., Silva Filho, A. F., Castro, N. A., Basei, M. S. (2006). Sm-Nd isotopic geochemistry, U-Pb and Ar40/Ar39 geochronology of Serra do Macaco Pluton: A Two-Mica Bearing Peraluminous Granitic Magmatism in the PE-AL Tectonic Domain, Borborema Province. $5^{\text {th }}$ South American Symposium on Isotope Geology, 139-143. Extended Abstracts.

Pearce, J., Harris, N. B. W., Tindle, A. D. (1984). Trace element discrimination diagrams for the tectonic interpretation of granitic rocks. Journal of Petrology, 25, 956-983. https:// doi.org/10.1093/petrology/25.4.956\}

Peccerillo, A., Taylor, S. R. (1976). Geochemistry of Eocene calc-alkaline volcanic rocks from the Kastamonu area, northern Turkey. Contributions to Mineralogy and Petrology, 58(1), 63-81. https://doi.org/10.1007/BF00384745

Rogers, N. W., Hawkesworth, C. J., Parker, R. J., Marsh, J. S. (1985). The geochemistry of potassic lavas from Vulsini, central Italy and implications for mantle enrichment processes beneath the Roman region. Contributions to Mineralogy and Petrology, 90(2-3), 244-257. https://doi.org/10.1007/ BF00378265

Sales das Neves, C. H. F., Ferreira, V. P., Neves, S. P., Correia, P. B. (2017). Mapeamento geológico auxiliado por imagens geofísicas e de satélite, aplicados a rochas ígneas: o exemplo do batólito Águas Belas-Canindé, domínio Pernambuco Alagoas, nordeste do Brasil. Estudos Geológicos, 27(2), 20-37.

Santos, E. J. (1996). Ensaio preliminar sobre terrenos e tectônica acrescionária na Província Borborema. XXXIX Congresso Brasileiro de Geologia, 6, 47-50. Anais. Salvador: SBG. 
Santos, E. J. (1998). Programa Levantamentos Geológicos Básicos do Brasil: carta Geológica. Escala 1:250.000 (Folha SC.24-X-A - Belém do São Francisco). Brasília: CPRM.

Santos, E. J., Nutman, A. P., Brito Neves, B. B. (2004). Idades SHRIMP U-Pb do Complexo Sertânia: implicações sobre a evolução tectônica da zona transversal, Província Borborema. Geologia USP. Série Cientifica, 4(1), 1-12. https://doi.org/10.5327/S1519-874x2004000100001

Schmidt, M. W. (1992). Amphibole composition in tonalite as a function of pressure: An experimental calibration of the Al-in-hornblende-barometer. Contributions to Mineralogy and Petrology, 110(2-3), 304-310. https://doi.org/10.1007/ BF00310745

Sial, A. N. (1986). Granite-types in northeast Brazil: current knowledge. Revista Brasileira de Geociências, 16(1), 54-72.

Sial, A. N. (1990). Epidote-bearing calc-alkaline granitoids in Northeast Brazil. Revista Brasileira de Geociências, 20(1-4), 88-100.

Silva, T. R., Ferreira, V. P., Lima, M. M. C. L., Sial, A. N., Silva, J. M. R. (2015). Synkinematic emplacement of the magmatic epidote bearing Major Isidoro tonalite-granite batholith: Relicts of an Ediacaran continental arc in the Pernambuco e Alagoas domain, Borborema Province, NE Brazil. Journal of South American Earth Sciences, 64, 1-13. http://dx.doi.org/10.1016/j.jsames.2015.09.002

Silva Filho, A. F., Guimarães, I. P., Ferreira, V. P., Armstrong, R. A., Sial,A. N. (2010). Ediacaran Águas Belas pluton, Northeastern Brazil: Evidence on age, emplacement. Gondwana Research, 17(4), 676-687. https://doi.org/10.1016/j.gr.2009.10.002

Silva Filho, A. F., Guimarães, I. P., Silva, J. M. R., Osako, L., Gomes, H. A., Luna, E. B. A. (2007). Nota Explicativa para a Folha Rio Una (escala 1:100.000 SC-24-X-B-V). Brasília: CPRM-PLGB, $141 \mathrm{p}$.

Silva Filho, A. F., Guimarães, I. P., Van Schmus, W. R. (2002). Crustal evolution of the Pernambuco-Alagoas complex, Borborema Province, NE Brasil: Nd isotopic data from Neoproterozoic granitoids. Gondwana Research, 5(2), 409-422. https://doi.org/10.1016/S1342-937X(05)70732-2

Silva Filho, A. F., Guimarães, I. P., Van Schmus, W. R., Armstrong, R. A., Rangel da Silva, J. M., Osako,
L. S., Concentino, L. M. (2014). SHRIMP U-Pb zircon geochronology and $\mathrm{Nd}$ signatures of supracrustal sequences and orthogneisses constrain the Neoproterozoic evolution of the Pernambuco-Alagoas domain, southern part of Borborema Province, NE Brazil. International Journal of Earth Science, 103(8), 2155-2190. http://dx.doi.org/10.1007/ s00531-014-1035-4

Silva Filho, A. F., Guimarães, I. P., Van Schmus, W. R., Dantas, E., Armstrong, R., Concentino, L. M., Lima, D. (2013). Long-lived neoproterozoic high-K magmatism in the Pernambuco-Alagoas Domain, Borborema Province, northeast Brazil. International Geology Review, 55(10), 1280-1299. https://doi.org/10.1080/00206814.2013.774156

Thompson, R. N. (1982). Magmatism of the British Tertiary volcanic Province. Scottish Journal of Geology, 18, 49-107. https://doi.org/10.1144/sjg18010049

Van Schums, W. R., Brito Neves, B. B., Hackspacher, P. C., Babinsky, M. (1995). U/Pb and Sm/Nd geochronlogic studies of the eastern Borborema Province, NE Brazil. Journal of African Earth Sciences, 8(3-4), 267-288. http:// dx.doi.org/10.1016/0895-9811(95)00013-6

Van Schmus, W. R., Kozuch, M., Brito Neves, B. B. (2011). Precambrian history of the Zona Transversal of the Borborema Province, NE Brazil: Insights from Sm-Nd and $\mathrm{U}-\mathrm{Pb}$ geochronology. Journal of South American Earth Sciences, 31(2-3), 227-252. https://doi.org/10.1016/j. jsames.2011.02.010

Van Schmus, W. R., Oliveira, E. P., Silva Filho, A. F., Toteu, S. F., Penaye, J., Guimarães, I. P. (2008). Proterozoic links between the Borborema Province, NE Brasil and the Central African Fold Belt. Geological Society of London, Special Publications, 294, 69-99. https://doi.org/10.1144/SP294.5

Watson, E. B., Harrison, T. M. (1983). Zircon saturation revisited: temperature and composition effects in a variety of crustal magma types. Earth and Planetary Science Letters, 64(2), 295-304. https://doi.org/10.1016/0012-821X(83)90211-X

Wilson, M. (1989). Igneous Petrogenesis: Global Tectonic Approach. Londres: Unwin Hyman, 466 p.

Wones, D. R. (1989). Significance of the assemblage titanite + magnetite + quartz in Granitic rocks. American Mineralogist, 74(7-8), 744-749. 